\title{
The discovery of a novel anti-metastatic Bcl3 inhibitor
}

Authors: Jitka Soukupováa ${ }^{1,2}$, Cinzia Bordoni ${ }^{1}$, Daniel Turnham ${ }^{2}$, William W. Yang ${ }^{2}$, Gillian Seaton $^{2}$, Aleksandra Gruca ${ }^{2}$, Rhiannon French ${ }^{2}$, Kok Yung Lee ${ }^{1}$, Athina Varnava ${ }^{2}$, Luke Piggott $^{2}$, Richard W. E. Clarkson ${ }^{2 \dagger}$, Andrew D. Westwell ${ }^{1 *}$, Andrea Brancale ${ }^{1 *}$

\section{Affiliations:}

${ }^{1}$ School of Pharmacy and Pharmaceutical Sciences, Cardiff University, Redwood Building, King Edward VII Avenue, Cardiff, CF10 3NB, Wales, U.K.

${ }^{2}$ European Cancer Stem Cell Research Institute, School of Biosciences, Cardiff University, Haydn Ellis Building, Maindy Road, Cardiff, CF24 4HQ, Wales, U.K.

$\dagger$ Corresponding author for biology.

†Corresponding author for chemistry.

*To whom correspondence should be addressed: e-mail: BrancaleA@cardiff.ac.uk

Running Title: Computer-aided discovery of a $\mathrm{Bcl} 3$ inhibitor.

Keywords: anti-metastatic; Bcl3; small molecule; Computer-aided drug design; in vivo.

Corresponding author address: Andrea Brancale, School of Pharmacy and Pharmaceutical Sciences, Cardiff University, Redwood Building, King Edward VII Avenue, Cardiff, CF10 3NB, Wales, U.K; tel: +442920874485; Fax:+442920874149; e-mail: BrancaleA@cardiff.ac.uk

Competing interests: RC, $\mathrm{AW}$ and $\mathrm{AB}$ were scientific advisers of Tiziana Life Sciences plc from 2014 to 2017. The other authors declare that they have no competing interests. The work described here has led to the filing of patent application WO2015014972 A1, "2Benzoylaminobenzamide derivatives as bcl-3 inhibitors" (inventors A.D.W., A.B., R.W.E.C, and J.S., publication date February 5, 2015). 


\begin{abstract}
The development of anti-metastatic drugs is an urgent healthcare priority for cancer patients, since metastasis is thought to account for around $90 \%$ of cancer deaths. Current antimetastatic treatment options are limited and often associated with poor long-term survival and systemic toxicities. Bcl3, a facilitator protein of the $\mathrm{NF}-\kappa \mathrm{B}$ family, is associated with poor prognosis in a range of tumor types. Bcl3 has been directly implicated in the metastasis of tumor cells, yet is well tolerated when constitutively deleted in murine models, making it a promising therapeutic target. Here we describe the identification and characterization of the first small molecule Bcl3 inhibitor, by employing a virtual drug design and screening approach against a computational model of the Bcl3-NFkB1(p50) protein-protein interaction. From selected virtual screening hits, one compound (JS6) showed potent intracellular Bcl3-inhibitory activity. JS6 treatment led to reductions in Bcl3-NFkB1 binding, tumor colony formation and cancer cell migration in vitro; and tumor-stasis and anti-metastatic activity in vivo, whilst being devoid of overt systemic toxicity. These results represent a successful application of in silico screening in the identification of protein-protein inhibitors for novel intra-cellular targets, and confirm $\mathrm{Bcl} 3$ as a potential anti-metastatic target.
\end{abstract}




\section{Introduction}

Despite significant advances in cancer drug therapy in recent years, treating tumor metastasis remains an area of significant unmet medical need. It is widely estimated that metastasis accounts for cancer deaths in around $90 \%$ of patients (1), yet historically treating metastasis has been considered a difficult challenge in part due to its association with late-stage disease and the absence of suitably targeted therapies. However recent advances in understanding of this complex multi-stage process, and some of the key molecular pathways potentiating the dissemination and colonisation of tumour cells, offers potential for early therapeutic intervention of metastasis in high-risk (short latency) disease as well as the possibility to target existing metastases in established disease $(1,2)$. Previous success in the development of new therapeutic agents targeting metastasis has been mainly restricted to agents that target existing disseminated lesions and establishment of the tumour microenvironment to support them. For example, bevacizumab (3), eribulin mesylate (4) and trastuzumab emtansine (5) showed initial promise in clinical trials in advanced breast cancer, yet offered only modest improvements to long-term survival benefits compared to established chemotherapy. The strategy of employing antimetastatic drugs to prevent the initial or ongoing dissemination of disease as early as possible, possibly in conjunction with existing chemotherapy, has gained traction in recent years. The successes of the RANKL (receptor activator of NF- $\mathrm{kB}$ ) inhibitory antibody and osteoporosis therapy denosumab (6), and the widely used bisphosphonates (7), in specifically reducing skeletal-related events (SREs) are notable although only limited to metastasis to the bone, while experimental agents targeting Rho/Rac mediated cell migration/invasion for example are effective at reducing metastasis in the pre-clinical setting but exhibit significant systemic toxicity in vivo (8). To ensure successful translation into a clinical setting, therefore, such interventions must overcome the dual problems of non-selective toxicity and cellular plasticity, for example when tumor cells adopt alternative modes of migration to overcome pharmacological inhibitors of cell motility $(9,10)$.

Recently we have described a non-redundant role for the $\mathrm{NF}-\kappa \mathrm{B}$ facilitator protein, $\mathrm{Bcl} 3$ in the multi-modal migration of metastatic breast cancer cells in vivo (11), whereby suppression of $\mathrm{Bcl} 3$ inhibits all forms of compensatory cell migration thus targeting metastatic seeding in vivo. Originally described as a key oncogenic translocation in B-cell lymphomas (12), Bcl3 has proven roles in a variety of haematological (13) and solid tumor cell types including breast $(14,15)$, colorectal (16), nasopharyngeal (17), ovarian (18), and prostate (19) cancers, and glioblastomas (20,21). Additionally, a recent study has implicated Bcl3 in progression of metastatic colorectal cancer through the maintenance of cancer stem cells (22). The fact that mouse models with constitutive $\mathrm{Bcl} 3$ deficiency are viable with only minor immunologic defects $(14,23)$, and the role of $\mathrm{Bcl} 3$ in induction of immune checkpoint PD-L1 expression (18), further substantiate the potential role of $\mathrm{Bcl} 3$ as a novel target for therapeutic intervention.

However, to date there have been no reported small molecule $\mathrm{Bcl} 3$ inhibitors, and mechanistic studies on Bcl3 biology have been limited to gene expression regulatory tools such as siRNA.

Inhibition of protein-protein interactions (PPIs) as a therapeutic strategy has emerged as a new frontier within drug discovery in recent years. It has long been recognized that specific proteinprotein interactions within cellular signaling pathways can drive disease progression. Recently, the previously held consensus that PPIs were rather large, flat and featureless interfaces not amenable to small molecule drug design has been challenged by the concept of key hotspot residues responsible for therapeutically relevant PPIs (24). The clinically approved microtubule 
inhibitors such as taxanes and vinca alkaloids (25), and Bcl2 homology domain (BH3) mimetic Venetoclax (26) provide further validation for this concept.

Here, we sought to devise a strategy to discover selective small molecule inhibitors of Bcl3 with anti-metastatic properties. Our studies focused on a key PPI between the ankyrin repeat domain of $\mathrm{Bcl} 3$ and its regulatory protein partner $\mathrm{p} 50$. The importance of this $\mathrm{Bcl} 3-\mathrm{p} 50$ interaction in driving Bcl3 function has been demonstrated through generation of p50 mutants (27) and an ankyrin repeat mutant of $\mathrm{Bcl} 3$ via site-directed mutagenesis (ANKM123), which when transfected into HEK293 cells lacks the ability to bind to p50 and mediate NF-кB signaling (28). Here we report a successful application of molecular modelling and in silico screening in the identification of JS6, the first small molecule protein-protein interaction inhibitor of $\mathrm{Bcl} 3$ and p50, with selective in vivo activity against metastatic progression in models of triple-negative breast cancer.

\section{Materials and Methods}

\section{Molecular Modelling}

All molecular modelling studies were performed on a MacPro dual $2.66 \mathrm{GHz}$ Xeon running Ubuntu 9. All protein crystal structures were downloaded from the PDB data bank (http://www.rcsb.org/). Hydrogen atoms were added to the protein and the ionization of residues were set appropriate to $\mathrm{pH} 7.4$, using Molecular operating Environment (MOE) (29), and minimized keeping all the heavy atoms fixed until a RMSD gradient of $0.05 \mathrm{kcal}$ mol- $1 \AA$ - 1 was reached. Protein complexes were built with MOE and minimized using the Amber 99 forcefield until a RMSD gradient of $0.05 \mathrm{kcal}$ mol-1 $\mathrm{A}-1$ was reached. Molecular dynamics were performed using Gromacs 4.5 (30) on the Bcl3-p50 complex using Gromos 96 forcefield and NPT working environment. The simulation was conducted at $300 \mathrm{~K}, 1$ atmosphere, and time step of 0.002 ps. The minimized structure was solvated in a periodic dodecahedron simulation box using spc 216 water molecules, providing a minimum of $9 \AA$ of water between the protein surface and any periodic box edge. Following minimization, the entire system was equilibrated for $100 \mathrm{ps}$ followed by a production phase of $5 \mathrm{~ns}$. The compound library was downloaded from the SPECS website (http://www.specs.net) and prepared used the Conformation Import function in MOE. The pharmacophore query was generated within MOE. The docking simulations were performed using GLIDE (31), saving three poses per ligand. Rescore was performed using PLANTS 1.1 (32) and FlexX (33) using default parameters.

\section{Chemical synthesis (JS6)}

General experimental: All chemical reagents and solvents were purchased from Sigma-Aldrich (Poole, UK) and used without further purification. Reaction progress was monitored by thinlayer chromatography using pre-prepared silica gel plates (Merck Kieselgel $60 \mathrm{~F}_{254}$ ), visualized with UV light ( 254 or $366 \mathrm{~nm}$ ). Final compound purification was carried out using flash column chromatography (silica gel 40-60 $\mu \mathrm{m}$, Merck) using the appropriate eluent mixture, or using the automated column chromatography Interchim PuriFlash 4000 system. ${ }^{1} \mathrm{H}$ NMR and ${ }^{13} \mathrm{C}$ NMR spectra were recorded using a Bruker AVANCE $(500 \mathrm{MHz})$ spectrometer auto-calibrated to the deuterated solvent reference peak. Chemical shifts $(\delta)$ are given in ppm relative to tetramethylsilane, and coupling constants ( $J$ values) are in Hz. Signal multiplicities are given as singlet (s), doublet (d), triplet (t), quartet (q), multiplet (m). Mass spectrometry was performed 
on a Bruker Daltonics microTOF instrument in positive mode, using electrospray ionization.

\section{Synthesis of JS6:}

Preparation of intermediate (3): To a stirred suspension of anthranilic acid (1; $1.0 \mathrm{~g}, 7.29 \mathrm{mmol})$ in pyridine $(10 \mathrm{~mL})$ was added 2-fluorobenzoyl chloride $(2 ; 2.54 \mathrm{~g}, 16.0 \mathrm{mmol})$. The reaction was stirred at room temperature for 5 hours, then poured slowly into a $10 \%$ solution of sodium carbonate $(50 \mathrm{~mL})$. The resulting precipitate was collected by filtration under reduced pressure, and the crude powder was washed three times with hexane to obtain the intermediate 2-(2fluorophenyl)-4H-benzo[ $d][1,3]$ oxazin-4-one (3) after drying, which was used without further purification.

Conversion of intermediate (3) to JS6: $N, N$-diisopropylamine $(0.72 \mathrm{~mL}, 0.536 \mathrm{~g}, 4.15 \mathrm{mmol})$ and 2-morpholinoethanamine $(0.60 \mathrm{~mL}, 0.594 \mathrm{~g}, 4.56 \mathrm{mmol})$ were added to a stirring solution of 2-(2-fluorophenyl)-4H-benzo[d][1,3]oxazin-4-one (3; $0.5 \mathrm{~g}, 2.07 \mathrm{mmol})$ in DMF (10 mL) at room temperature. After stirring for 18 hours, the reaction mixture was diluted with water (50 $\mathrm{mL})$, extracted with ethyl acetate $(50 \mathrm{~mL})$, washed three times with brine $(3 \times 50 \mathrm{~mL})$, dried $\left(\mathrm{MgSO}_{4}\right)$ and concentrated in vacuo to give crude 2-fluoro-N-(2-((2-morpholinoethyl)carbamoyl)phenyl)benzamide (JS6). Purification by column chromatography using chloroform:methanol (9:1) as eluent provided pure JS6 as a white powder in 75\% yield, with spectroscopic and analytical data corresponding to the purchased sample (www.specs.net). ${ }^{1} \mathrm{H}$ $\mathrm{NMR}\left(\mathrm{CDCl}_{3}\right) \delta 2.50\left(4 \mathrm{H}, \mathrm{t}, \mathrm{J}=4.5 \mathrm{~Hz}, 2 \mathrm{xCH}_{2} \mathrm{~N}\right), 2.61\left(2 \mathrm{H}, \mathrm{t}, \mathrm{J}=5.9 \mathrm{~Hz}, \mathrm{CH}_{2} \mathrm{~N}\right), 3.54(2 \mathrm{H}, \mathrm{m}$, $\left.\mathrm{CH}_{2} \mathrm{NH}\right), 3.72\left(4 \mathrm{H}, \mathrm{t}, \mathrm{J}=4.5 \mathrm{~Hz}, 2 \mathrm{xCH}_{2} \mathrm{O}\right), 6.98(1 \mathrm{H}, \mathrm{m}, \mathrm{ArH}), 7.14(1 \mathrm{H}, \mathrm{t}, \mathrm{J}=7.5 \mathrm{~Hz}, \mathrm{ArH})$, $7.19(1 \mathrm{H}, \mathrm{ddd}, \mathrm{J}=11,8.5,1.2 \mathrm{~Hz}, \operatorname{ArH}), 7.28(1 \mathrm{H}, \mathrm{d}, \mathrm{J}=7.5 \mathrm{~Hz}, \operatorname{ArH}), 7.51(3 \mathrm{H}, \mathrm{m}, \operatorname{ArH}), 8.04$ $(1 \mathrm{H}, \mathrm{td}, J=7.5,1.8 \mathrm{~Hz}, \mathrm{ArH}), 8.74(1 \mathrm{H}, \mathrm{d}, J=8.0 \mathrm{~Hz}, \mathrm{NH}), 11.80\left(1 \mathrm{H}, \mathrm{d}, \mathrm{J}=7.0 \mathrm{~Hz}, \mathrm{NH} .{ }^{19} \mathrm{~F}\right.$ $\mathrm{NMR}(\mathrm{CDCl} 3) \delta 112.48 .{ }^{13} \mathrm{C} \mathrm{NMR}\left(\mathrm{CDCl}_{3}\right) \boldsymbol{\delta}: 36.01\left(\mathrm{CH}_{2} \mathrm{NH}\right), 53.28\left(2 \mathrm{xCH}_{2} \mathrm{~N}-\right.$ morph$), 56.64$ $\left(\mathrm{CH}_{2} \mathrm{~N}\right), 66.94\left(2 \mathrm{xCH}_{2} \mathrm{O}\right), 116.52\left(\mathrm{~d},{ }^{2} \mathrm{~J}_{\mathrm{C}-\mathrm{F}}=23.38 \mathrm{~Hz}, \mathrm{ArCH}\right), 121.97(\mathrm{ArC}), 122.44(\mathrm{ArCH})$, $122.76\left(\mathrm{~d},{ }^{2} \mathrm{~J}_{\mathrm{C}-\mathrm{F}}=12.38 \mathrm{~Hz}, \mathrm{ArC}\right), 123.39(\mathrm{ArCH}), 124.62\left(\mathrm{~d},{ }^{3} \mathrm{~J}_{\mathrm{C}-\mathrm{F}}=3.63 \mathrm{~Hz}, \mathrm{ArCH}\right), 126.66$ $(\mathrm{ArCH}), 131.49\left(\mathrm{~d},{ }^{4} \mathrm{~J}_{\mathrm{C}-\mathrm{F}}=2.25 \mathrm{~Hz}, \operatorname{ArCH}\right), 132.29(\mathrm{ArCH}), 133.37\left(\mathrm{~d},{ }^{3} \mathrm{~J}_{\mathrm{C}-\mathrm{F}}=8.89 \mathrm{~Hz}, \operatorname{ArCH}\right)$, 139.00 (ArC), $160.33\left(\mathrm{~d},{ }^{1} \mathrm{~J}_{\mathrm{C}-\mathrm{F}}=249.63 \mathrm{~Hz}, \mathrm{ArC}-\mathrm{F}\right), 162.30(\mathrm{C}=\mathrm{O}), 168.66(\mathrm{C}=\mathrm{O}) . \mathrm{MS}\left(\mathrm{ESI}^{+}\right)$ $372.2[\mathrm{M}+\mathrm{H}]^{+}\left(\mathrm{C}_{20} \mathrm{H}_{22} \mathrm{FN}_{3} \mathrm{O}_{3}\right)$.

Preparation of JS6 for biological assays: JS6 was prepared for cell culture and in vivo assays by diluting powdered compound in DMSO to a concentration of $100 \mathrm{mg} / \mathrm{mL}$ and diluted immediately before use in either cell culture medium (in vitro) or sterile water (in vivo).

\section{Cell culture and plasmid reagents}

The human embryonic kidney cell line HEK-293 (ATCC CRL-1573) was maintained in DMEM (Invitrogen) and the human breast cancer cell lines MDA-MB-231 (TNBC-ATCC HTB-26), MDA-MB-436 (TNBC-ATCC HTB-130), SKBR3 (ATCC HTB-30), BT474 (ATCC HTB-20) and HCC1954 (HER2-CRL-2338) were maintained in Hybi-Care or McCoy's 5a media (HTCC) or RPMI (Invitrogen, Paisley, UK) in the absence of antibiotics at $37^{\circ} \mathrm{C}$ according to ATCC guidance. The murine mammary tumour cell line 4T1.2 (TNBC) was a kind gift from R.Anderson (Peter MacCallum Cancer Centre, Aus). Plasmids containing either wild type (WT) Bcl-3 or the Bcl-3 ANK M123 non-binding mutant sequences contained within a FLAG-tagged pcDNA 3.1 backbone vector were gifted from Dr. Alain Chariot (Interdisciplinary Cluster for Applied Genoproteomics, University of Liège, Belgium). In order to achieve Bcl-3 knockdown in cell lines, respective cells were transfected with ON-Target plus SMART pool (Dharmacon, Thermo Scientific, Lafayette, USA) or scrambled siRNA control (32 nM) using lipofectamine RNAiMAX (Invitrogen, Paisley, UK) according to the manufacturer's protocol. To generate 
cells overexpressing either Bcl-3 WT or Bcl-3 ANK M123, cells were transfected using Lipofectamine LTX reagent (Invitrogen, Paisley, UK). Stably transfected cells were selected by the addition of neomycin (G418, Sigma, Dorset, UK) to the culture medium for at least 7 days.

\section{Bcl3 ELISA}

Non-denatured cell lysate was diluted with TBS (Calbiochem, Watford, UK) supplemented with $0.5 \% \mathrm{v} / \mathrm{v}$ Tween (Sigma, Dorset, UK) to a concentration of $0.5-1 \mu \mathrm{g} / \mu \mathrm{L}$ and $100 \mu \mathrm{L}$ was added onto ANTI-Flag coated flat bottom ELISA plates (Sigma, Dorset, UK). Wells were cultivated at $37^{\circ} \mathrm{C}$ for an hour followed by $3 \times 200 \mu \mathrm{L}$ washes with TBS/Tween. Primary antibodies, either Bcl-3 (1:30 Santa Cruz Biotechnology, CA sc-185) for indirect ELISA or p50 for sandwich ELISA (1:200 Abcam, Cambridge, UK ab 7549), were covered from light for an hour at room temperature. Following three $200 \mu \mathrm{L}$ washes with TBS/Tween, alkaline phosphatase conjugated secondary antibody was incubated then wells washed with $3 \times 200 \mu \mathrm{L}$ TBS/Tween. pNPP solution (Santa Cruz Biotechnology, CA) was added (50 $\mu \mathrm{L} /$ well) and cultivated for an hour covered from light at room temperature. The reaction was stopped by addition of $3 \mathrm{~N} \mathrm{NaOH}(20 \mu \mathrm{L} / \mathrm{well})$ and the colometric changes were measured at $405 \mathrm{~nm}$ using a plate reader.

\section{Bcl-3 immunoprecipitation}

Adherent cell lines were cultured in $60 \mathrm{~mm}$ dishes then cells were rinsed with ice cold PBS, and scraped off in $1 \mathrm{~mL}$ ice cold PBS, and spun at $4{ }^{\circ} \mathrm{C}$. Cell pellets were re-suspended in $400 \mu \mathrm{L}$ of pre-chilled lysis buffer (20 mM HEPES pH7.9, $100 \mathrm{mM} \mathrm{NaCl}, 20 \%$ glycerol, $1 \mathrm{mM} \mathrm{MgCl} 2,0.5$ mM EDTA, 0.1 mM EGTA, 1\% NP-40). The suspension was placed on ice for 30-45 mins and insoluble material pelleted for 10 mins at $4^{\circ} \mathrm{C} .100 \mu \mathrm{L}$ protein A-sepharose bead (GE Healthcare Life Sciences, Amersham, UK) suspension was added to $200 \mu \mathrm{L}$ of lysates, agitated at $4{ }^{\circ} \mathrm{C}$ for 30-45 mins then spun for 3 mins and the supernatant transferred, discarding pelleted beads. 10 $\mu \mathrm{L}$ of Bcl-3 primary antibody and $5 \mu \mathrm{L}$ of p50 antibody was added to separate aliquots of 100 $\mu \mathrm{L}$ lysate and incubated overnight at $4{ }^{\circ} \mathrm{C}$ under agitation. Following centrifugation for $3 \mathrm{~min}$, beads were washed 3 times in lysis buffer and re-spun. The pellet was re-suspended in $5 \mathrm{x}$ Laemmli buffer and boiled at $95{ }^{\circ} \mathrm{C}$ for 5 mins. $25 \mu \mathrm{g}$ of protein was loaded per well of Western blots and incubated with antibodies against Bcl-3 (1:200 Proteintech, Rosemont, USA 23959-1AP) or p50 (1:500 Cell Signalling, Danvers, MA 3035) in 5\% w/v non-fat milk powder in $\mathrm{PBS} / \mathrm{Tw}$ een. Membranes were incubated in the primary antibody solution overnight at $4{ }^{\circ} \mathrm{C}$ on a roller.

\section{NF- $\mathrm{kB}$ reporter assay}

Cells were seeded into clear bottom black walled 96-well plates (Corning Inc., Lowell, US) in antibiotic free culture media $\left(1-2 \times 10^{5}\right.$ cells/mL). After 24 hours, cells were transfected with NF$\kappa \mathrm{B}$ reporter plasmid (34) as previously described (35). Briefly the NFผB reporter plasmid pLTRX-Luc (10 ng/well) was used with pcDNA3.1-LacZ plasmid (10 ng/well) to normalize for transfection efficiency. For positive and negative controls respectively, 10ng of pGL3control or pGL3basic were transfected in place of the reporter plasmid. After 48 hours post-transfection cells were lysed using Glo-lysis buffer and analysed using Beta-glo and Bright-glo according to manufacturer's protocol (Promega, Hampshire, UK). Luminescence relative to LacZ was read using a Flurostar Optima plate reader (BMG Labtech, Aylesbury, UK) and displayed as relative light units (RLU). 


\section{Migration assay}

Single cell timelapse, boyden chamber and wound-healing (scratch) assays were performed as previously described (15). For in situ boyden chamber assays, cells were seeded in low serum media in an $8 \mu \mathrm{m}$ pore chamber coated with Matrigel Basement Membrane Matrix (BD Biosciences, Oxford; BioCoat). The cell insert was placed into a well with $750 \mu \mathrm{L}$ of complete growth media containing $10 \%$ of serum of a 24 well cell culture insert companion plate (BD Biosciences, Oxford, UK). $350 \mu \mathrm{L}$ of cells $\left(2 \times 10^{5}\right.$ cells $\left./ \mathrm{ml}\right)$ were re-suspended in normal growth media containing $0.1 \%$ serum and plates incubated for $24 \mathrm{hrs}$ at $37{ }^{\circ} \mathrm{C}$ and $5 \% \mathrm{CO}_{2}$. Cells were fixed with 70\% ice-cold ethanol and stained with Harris' Haematoxylin (Sigma, Dorset, UK) and $0.5 \%$ filtered Eosin (Sigma, Dorset, UK) for 2 min. Membranes were mounted on slides with glycerol gelatin.

\section{Cell viability assay}

CellTiter-Blue ${ }^{\circledR}$ cell viability assay (Promega, Hampshire, UK) was performed in 96-well plates using $100 \mu \mathrm{L}$ of media and $20 \mu \mathrm{L}$ Cell Titre Blue reagent for an hour at $37^{\circ} \mathrm{C}$ in $5 \% \mathrm{CO}_{2}$.

\section{Colony formation}

Cells were seeded at low density ( 250 cells $/ \mathrm{mL}$ ) in 6-well format in complete growth medium and incubated for 10 days. Quantification of colonies involved aspiration of culture media, washing the cells gently with PBS, followed by fixation of colonies with glutaraldehyde (6\% $\mathrm{v} / \mathrm{v})$ and staining with crystal violet $(0.5 \% \mathrm{w} / \mathrm{v})$ for $15 \mathrm{mins}$ at room temperature.

\section{Murine transplantation studies}

All animal procedures were carried out in accordance with the UK Home Office in compliance with the Animals Scientific Procedures Act of 1986 under the UK HO project licence number 3003433. Athymic Nude (Hsd:Athymic Nude-Foxn1nu) mice were obtained from Envigo Laboratories (Alconbury, UK). Balb/c-SCID and Balb/c (AnNCrl) mice were obtained from Charles River (Harlow, UK). Animals were acquired at six to eight weeks of age and maintained in individually ventilated cages (Allentown Inc. NJ, US) with a $12 \mathrm{hr}$ day/night cycle. Mice received a Teklad global 19\% protein extruded rodent diet (Envigo, Alconbury, UK) and water ad libitum. Bilateral subcutaneous orthotopic xenografts were performed with $1 \times 10^{6}$ MDA-MB436, MDA-MB-231-Luc and HCC1954-Luc cells suspended in $100 \mu \mathrm{L}$ RPMI and $100 \mu \mathrm{L}$ Matrigel (ThermoFisher, Waltham, MA). Bilateral subcutaneous orthotopic allografts were performed with $5 \times 10^{5} 4 \mathrm{~T} 1.2$ cells suspended in $100 \mu \mathrm{L}$ RPMI. Mice were measured two to three times weekly for tumors with digital callipers and volume calculated using the formula: Volume $=\left(\right.$ Length $\mathrm{x}\left(\mathrm{Width}^{2}\right)$. Experimental metastases were established by intravenous injection of $2 \times 10^{5}$ MDA- MD-231-Luc cells into Athymic Nudes. Cells were suspended in 100 $\mu \mathrm{L}$ of RPMI media and injected via the tail vein of 8-week old female mice. Metastatic progression to distal organs was assessed through bioluminescence imaging with the IVIS Spectrum In Vivo Imaging System (Perkin Elmer, Bucks, UK) and histological analysis of H\&E stained paraffin embedded sections. Prior to imaging, an intraperitoneal injection of $100 \mu \mathrm{L} D-$ luciferin was administered to each animal. The mice were then anaesthetised with $2.5 \%$ isoflurane, oxygen mix and imaged with the charge-coupled IVIS camera device selecting an exposure time of 2 minutes. Luminescence signal was measured through region of interest selection and quantified as total flux. Mice were treated in vivo daily with either JS6 or DMSO control via intra-peritoneal injection in sterile water. 
Statistical methods. In all statistical comparisons unpaired student's tests were applied assuming equal variance.

\section{Results}

\section{Computational design of small molecule inhibitors targeting the Bcl3-p50 interaction site}

NF- $\kappa \mathrm{B}$ transcription factor complexes can both induce and repress gene expression by binding to DNA sequences known as $\kappa B$ elements, leading to the regulation of numerous genes controlling processes such as apoptosis, cell adhesion, proliferation, immunity and inflammation (35). For this reason, inhibition of the NF- $\mathrm{NB}$ signaling pathway has been pursued as a therapeutic strategy for a variety of pathologies, including cancer, although to date there is no selective NF- $\mathrm{BB}$ pathway inhibitor approved for human use, largely due to toxicity concerns associated with inhibiting global NF- $\kappa$ B pathway activation (36). For this reason, we sought to develop a more selective approach to pathway inhibition, based on targeting the NF- $\kappa \mathrm{B}$ pathway co-activator $\mathrm{Bcl} 3$ and its interacting protein partners, given our previous work demonstrating the viability of $\mathrm{Bcl} 3$ knockdown in mouse models (14). Bcl3 is known to modulate transcription through binding to the NF- $\mathrm{KB}$ family proteins p50 and p52; these key protein-protein interactions (PPIs) provided the starting point for our computational design work.

The crystal structure of the ankyrin repeat domain (seven repeats) of $\mathrm{Bcl} 3$ was solved previously at a resolution of $1.86 \AA$ (PDB code $1 \mathrm{~K} 1 \mathrm{~A}$ ) spanning from residues 119-359 (37). The N- and Cterminal domains have not be crystallized to date, however numerous mutagenesis studies have shown that the ankyrin repeat of $\mathrm{Bcl} 3$ is sufficient for interaction with its binding partners (3841). The structurally most similar member of the I $\mathrm{K} B$ family, $\mathrm{I} \kappa \mathrm{B} \alpha$, has only six ankyrin repeats, but shares $35 \%$ sequence identity over these repeats. The crystal structure of Bcl-3 in a complex with its binding partners is not yet available, therefore we used the structure of I $\mathrm{B} \alpha$ crystallized in a complex with p65/p50 heterodimers as a template for construction of our model within the MOE platform (29). Initially, we prepared the Bcl3/p50 complex by aligning and superposing the crystal structure of the $\mathrm{Bcl} 3$ ankyrin repeat (PDB: 1K1A) to the corresponding domain of $\mathrm{IKB} \alpha$ (PDB: 1NFI) (42), crystallized in complex with p50. Removal of the IKB $\alpha$ portion revealed the putative complex between $\mathrm{Bcl} 3$ and $\mathrm{p} 50$. Two molecules of $\mathrm{Bcl} 3$ have been observed to bind a single p50 homodimer (43), therefore a second molecule of Bcl3 was added using pseudo-dyad symmetry of the p50 homodimer as published previously (44) (Figure 1A). The model was then refined using a short molecular dynamics (MD) simulation (5 ns) to relax the contacts between $\mathrm{Bcl} 3$ and p50 (30). The Bcl3/p50 dimer interface exhibits an extensive network of hydrophobic interactions and hydrogen bonds within ankyrin repeat 4 and 7 . Importantly, we observed a hydrophobic binding pocket within ankyrin repeat 6 and 7. This observation was of particular interest as ІкВ $\alpha$ does not share structural similarity within this area, therefore it can serve as a unique target on $\mathrm{Bcl} 3$. The interacting residues within the binding pocket contain p50 residues (mainly Lys 275, Asp 297, Ser 299, Pro 300, Thr 301, Asp 302, Val 303, His 304, Arg 305) interacting with Bcl-3 residues from the ankyrin repeat six (Met 298, Tyr 299, Ser 300, Gly 301, Ser 302, Ser 303, His 306, Ser 307) and unique ankyrin repeat seven (Asn 331, Cys 332, His 333, Asn 334, Asp 335, Val 340, Arg 342). 
The final state of the MD simulation was energy minimized and used as the input protein structure in a virtual screening protocol. As a binding site for molecular docking, we selected the interface between p50 and ankyrin repeats 6-7 of $\mathrm{Bcl} 3$, corresponding to Pro300 and Thr301 of p50 (Figure 1B). The first step of the virtual screening was the filtration of the SPECS library of compounds ( $\sim 360,000$ structures) through a pharmacophore query developed on the interaction between p50 and Bcl3 in the selected pocket (Figure 1C). The resulting 27,013 structures were refined by selecting the molecules with a molecular weight between 200 and 450, and clustering the remaining compounds based on a minimum of 95\% identity (Tanimoto index). Molecular docking, using GLIDE (31), was then performed on the 16,058 remaining structures. Docking results were rescored using the scoring functions of two other docking softwares (FlexX and PLANTS), and the 121 compounds that were present within the top $10 \%$ of all the different scoring ranking were visually inspected $(42,43)$. This process led to the selection of 10 molecules (denoted as JS1-JS10) that appear to fit the pocket in a very similar way as the corresponding p50 residues (Figure 1D).

\section{Inhibition of Bcl3:p50 protein binding and cellular cytotoxicity}

The ten shortlisted compounds from the computational screening and docking studies were purchased from the SPECS library and assessed for their ability to inhibit Bcl3:p50 proteinprotein interaction using an ELISA-based assay (Figure 2). Initially we assessed the effect of the virtual hit compounds on cellular Bcl3 levels. HEK293 cells overexpressing FLAG-tagged Bcl3 (Supp Fig 1A, 1B) were incubated with each of the test compounds at $10 \mu \mathrm{M}$ or vehicle control for 24 hours, comparing to untreated HEK293 cells expressing either a dominant negative FLAG-tagged Bcl3 ANK mutant (28) or empty vector control (-Bcl3). ELISA assay results on cell lysates, using an immobilized FLAG-tag antibody and a specific Bcl3 detection antibody are shown (Figure 2A). None of the test compounds caused a significant decrease in cellular Bcl3 levels compared to untreated control.

Next we investigated the ability of the candidate compounds to specifically interfere with the protein-protein interaction (PPI) between $\mathrm{Bcl} 3$ and p50, using an NF- $\mathrm{B}$ (p50) antibody-based sandwich ELISA assay to detect p50:Bcl3-FLAG complexes (Figure 2B). The ELISA data showed that 4 of the 10 compounds identified from computational screening significantly inhibited p50:Bcl3 PPI, with compound 6 (JS6) most effectively inhibiting the interaction, equivalent to the ANK binding mutant negative control. The specific reduction in p50:Bcl3 PPI was confirmed by an immunoprecipitation assay of the breast cancer cell line MDA-MB-231 pre-treated with JS6 for either 30 minutes or 2 hours using polyclonal antibodies to endogenous $\mathrm{Bcl} 3$ and p50 (Figure 2C). A reduction in p52:Bcl3 PPI was also observed following 2 hours incubation with JS6, but not at 30 minutes, confirming the modelling prediction that both p50 and p52 interactions are disrupted, but suggesting a marginal difference in kinetics of inhibition for the two NF- $\kappa$ B subunits (Supp. Figure 1C). Treatment with JS6 for 24 hours was also found to be non-cytotoxic when tested in non-tumorigenic HEK293 (Figure 2D) and breast MCF10A cells (Supp. Figure ), while breast cancer MDA-MB-231 triple-negative breast cancer cells exhibited a small but statistically insignificant reduction in cell viability according to the CellTiter-Glo® luminescent cell viability endpoint assay (Figures $2 \mathrm{D}$ and $2 \mathrm{E}$ ). The noninhibitory compound JS1, which was confirmed to have no inhibitory effect on p50:Bcl3 PPI by co-immunoprecipitation assay (Supp Fig 1D) was used in subsequent assays as a negative control for JS6. 


\section{Inhibition of cellular NFאB signaling by JS6}

Having established the ability of compound 6 (JS6) to block Bcl3:p50 binding interactions, we proceeded to investigate the effects of JS6 on downstream cellular events. To determine the

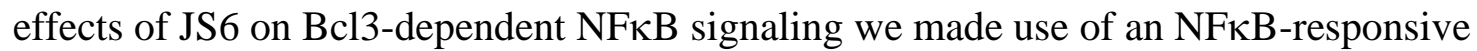
luciferase reporter assay (35), following JS6 treatment $(10 \mu \mathrm{M}, 24$ hours) of the following human Bcl3 overexpressing cell lines: HEK293; HEK293 co-overexpressing NFkB1/p52; and the breast cancer cell line MDA-MB-231 (Figure 3). Overexpression of Bcl3 in all cell lines resulted in an expected increase in NF- $\kappa \mathrm{B}$ reporter activity, which was sequestered by coadministration of JS6 in a dose dependent manner (Figure 3A-F). Overexpression of NFkB1/p52 in HEK293 cells which lack endogenous p52, augmented Bcl3-mediated NFkB activity (Supp Fig 1E). This p52-mediated response was also sequestered by JS6 (Figure 3C) but was not affected by the non-inhibitory compound JS1 (Supp. Figure 1F). Half-maximal responses to JS6 were obtained in the range $45 \mathrm{nM}-710 \mathrm{nM}$ across the three cell lines.

To confirm the specificity of JS6 on Bcl3 mediated transcription we compared the responses of nine genes previously identified to be either positively or negatively regulated by $\mathrm{NF}-\kappa \mathrm{B} / \mathrm{Bcl} 3$ (45-47) by treating MDA-MB-231 cells with JS6 or Bcl3-specific siRNA (Supp. Figure 1F). The transcriptional signature of the nine gene panel from JS6 treated cells closely resembled that of the Bcl3-siRNA control, with seven of the nine genes exhibiting similar amplitudes of response (Figure 3G). Furthermore, JS6 led to a small but significant decrease in Cdc42 (Supp. Figure $1 \mathrm{G}$ ) which we had recently identified as a novel $\mathrm{Bcl} 3$ gene target mediating the promigratory effects of $\mathrm{Bcl} 3$ in breast cancer cells (11).

\section{Inhibition of tumour cell migration by JS6}

To establish whether these transcriptional responses to JS6 manifested in a concomitant reduction in multi-modal cell migration, thus phenocopying the effects of Bcl3-siRNA previously observed in breast cancer cells $(11,14,15)$ we investigated the effect of JS6 in singlecell (transwell) assay (Figure 4A, Supp. Figure 2A-C), single-cell (mesenchymal) assay (Figure 4C, Supp. Figure 1D) and collective sheet (wound-healing) assay (Figure 4D-F). JS6 significantly suppressed all modes of cell migration. Single-cell motility, the preferred migratory state of MDA-MB-231 and MDA-MB-436 cells (11), was most profoundly affected by JS6, with a half-maximal dose of $310 \mathrm{nM}$ relative to the dominant negative Bcl3 ANK-mutant and siRNAmediated knockdown of Bcl3 expression (Figure 4A-C). Similar responses were observed with collective sheet migration of mesenchymal-like TNBC cells and the HER2-positive cell line BT474 (Figure 4D-F). The non-inhibitory compound JS1 failed to demonstrate effects on cell migration in these cell lines (Figure 4D-F). This supports the previously described nonredundant role for Bcl3 in multi-modal cell motility phenotypes (11) and confirms efficacy of JS6 in both TNBC and HER2-positive breast cancer cells.

\section{In vivo anti-metastatic and anti-tumor activity of JS6}

Consistent with its role in cell migration, we and others have previously demonstrated that $\mathrm{Bcl} 3$ plays a key role in the metastatic progression of breast cancer $(14,15)$. Thus, following establishment of the Bcl3-p50 inhibitory activity of JS6, leading to suppression of cellular NFkB signaling and anti-migratory phenotypes, we wished to investigate the potential for this 
compound to disrupt the metastatic process in vivo, using murine models of metastatic breast cancer. Given the requirement for larger (gram scale) quantities of JS6 for in vivo work at this stage, we additionally developed a straightforward two-step synthetic route to JS6 from commercially available starting materials (Figure 5A). This allowed analytical and spectroscopic comparison between synthetic and commercially available samples for further authentication and validation of results. In addition, the synthetically prepared sample was assessed in the in vitro migration assay described above, showing a comparable activity to the commercially procured sample.

Reaction of anthranilic acid (1) with 2-fluorobenzoyl chloride (2) in basic solvent (pyridine) at room temperature gives the intermediate 2-(2-fluorophenyl)-4H-benzo[ $d][1,3]$ oxazin-4-one (3) in $65 \%$ yield. Nucleophilic ring opening of intermediate $(3)$ with 2-morpholinoethan-1-amine and $N, N$-di(isopropyl)ethylamine (DIPEA) in DMF at room temperature gave pure 2-fluoro-N(2-((2-morpholinoethyl)-carbamoyl)phenyl)benzamide (JS6) in 75\% yield following final purification using column chromatography.

Using an established model of experimental metastasis, MDA-MB-231 cells were inoculated intravenously into immunocompromised mice. JS6 $(3.5 \mathrm{mg} / \mathrm{Kg})$ or vehicle control (1\% DMSO) was given as a single daily intra-peritoneal injection for 10 days immediately following tumor cell inoculation and scanned for luciferase activity over the following 49 days (Figure 5B). Twenty-eight days after inoculation of tumor cells, the majority of JS6 treated mice were essentially devoid of detectable lung metastases (Figure 5C, 5D) representing an $83 \%$ reduction in overall thoracic tumor burden in the JS6 treated cohort compared to untreated mice. After a further 28 days a minority of JS6 treated mice (31\% compared to 92\% untreated) subsequently developed thoracic lesions that were on average $41 \%$ smaller than extant untreated tumors (Figure 5E+F).

This reduction in the establishment and subsequent expansion of disseminated tumors was also observed in breast tumors seeded orthotopically. Two triple-negative breast cancer cell lines, MDA-MB-436 (Figure 5G-J) and MDA-MB-231 (supp. Figure 3A-D) and a HER2-positive breast cancer cell line HCC1954 (supp. Figure 3F-G) were inoculated into the mammary fat pads of recipient mice receiving daily doses of $3.5 \mathrm{mg} / \mathrm{Kg}$ JS6 for up to 60 days following tumor seeding. Systemic JS6 treatment resulted in a 66\% reduction in MDA-MB-436 tumor volume (Figure 5H, 5I), a 38\% reduction in MDA-MB-231 tumor volume and a $48 \%$ reduction in HCC1954 tumor burden (supp. Figure 2) with no overt signs of toxicity (supp. Figure 4). This reduction in tumor growth correlated with a decrease in tumor cell turnover index as measured by the relative extent of apoptosis (cleaved caspase 3) and mitosis (phospho-histone H3) within the tumors (Figure 5J and Supp. Figure 3D), with the major component of this response being the effect of JS6 on apoptosis rates.

The effects of JS6 on experimental seeding and clonal expansion of tumor cells in vivo in xenograft models were confirmed in an immune-competent murine model of spontaneous metastasis (Figure 6A). The metastatic murine mammary carcinoma cell line 4T1.2 (48) was orthotopically transplanted into the mammary fatpads of recipient Balb/c mice and JS6 administered by intraperitoneal route at $3.5 \mathrm{mg} / \mathrm{Kg}$ and $10 \mathrm{mg} / \mathrm{Kg}$ daily for the duration of the experiment. Mammary tumor growth was reduced by $58 \%(+/-3 \%)$ and $87 \%(+/-5 \%)$ respectively, consistent with the reduction in tumor growth seen in human TNBC xenografts. Moreover, spontaneous metastatic tumor burden arising from the primary orthotopic tumor and disseminated to the lungs was also inhibited by JS6 administration (Figure 6C), with a 38\% (+/- 
$2 \%)$ reduction in metastatic tumor burden at $3.5 \mathrm{mg} / \mathrm{Kg}$ and a $93 \%(+/-4 \%)$ reduction in metastatic tumors at $10 \mathrm{mg} / \mathrm{kg}$ JS6. This demonstrates the efficacy of JS6 on inhibiting spontaneous tumor metastasis, equivalent to the prevention of circulating tumor cell dissemination observed in xenograft models (Figure 5). Furthermore, the average size of metastatic lesions detected in lung tissues were significantly impacted by JS6, with an approximate $50 \%$ reduction in the size of $10 \mathrm{mg} / \mathrm{Kg}$ JS6 treated tumors (Figure 6D). Moreover, the demonstration of JS6 efficacy in murine mammary tumors in vivo, confirms tumor specificity and the lack of toxicity observed in mice treated daily with JS6 (Supp. Figure 4).

The effect of JS6 on tumor seeding and clonal expansion were confirmed in colony formation assays in vitro (Figure 6E, Supp. Figure 2E). JS6 exhibited a dose dependent inhibition of colony formation and growth in MDA-MB-231 and MDA-MB-436 cell lines. Significant inhibition of colony formation in vitro was observed in the micromolar range of JS6, which likely reflects a requirement to maximally load cells with inhibitor in order to impact on longterm tumor cell proliferation and is consistent with the relative impact of JS6 on tumor metastasis in vivo. These data combined are consistent with previous observations of the effects of Bcl3 inhibition on cancer-stem-like cells in colorectal cancer cell lines (22) and confirm antitumor effects of a novel Bcl3 inhibitor which impacts on in vivo tumor cell seeding and colonization.

\section{Discussion}

In this paper, we report the anthranilic acid derivative JS6 as the first small molecule Bcl3 inhibitor in metastatic breast cancer models. JS6 was identified via virtual library screening of a computational Bcl3/p50 protein-protein interface model (Figure 1). We provide evidence of its efficacy as a Bcl3 (ankyrin repeat domain)/p50 inhibitor in vitro (Figure 2, 3), and as an inhibitor of downstream Bcl3 cellular functions and metastatic progression in animal models in vivo (Figure 5 and 6). Consistent with the growing evidence of Bcl3's role in a variety of solid tumors (refs. 14-21) this study highlights a dual role for Bcl3 in tumor progression, promoting both tumor growth and metastasis. While this likely reflects the pleiotropic effects of NF-kB signaling more widely it remains to be determined whether the impact of inhibiting $\mathrm{Bcl} 3$ is mediated primarily through one or both of the NF-kB canonical/non-canonical pathways or indeed whether there are alternative functions of $\mathrm{Bcl} 3$ as yet to be determined. What is clear however is that targeting Bcl3 in this manner is well tolerated (Supp. Figure 4; ref. 14,23).

These data shows that it is possible to use a multi-modular computational screening approach to identify a relatively high proportion of functional hit compounds, with in vivo efficacy. The in vivo data presented are consistent with the concept of JS6 as a lead compound with optimal activity in the prevention of metastatic outgrowth, as opposed to shrinkage of established metastases. Whilst it is intuitive that a drug candidate should have optimal activity at the early stages of metastatic disease, this does present some particular challenges in moving forward towards clinical development. First, the activity of JS6 (or a related analogue) in clinic development might be optimally targeted to cancer types characterized by early metastatic progression. These might include short latency cancer types such as triple-negative and HER-2 positive breast cancer, or other cancer types where Bcl-3 plays a key role and where metastatic progression occurs within a few months rather than years, e.g. pancreatic and nasopharyngeal 
cancer. The requirement for "short latency", poor prognosis tumor types reflect the realities, costs and timescales of clinical development.

The compound discovered in this study (JS6; molecular weight $=371.4$ ) presents a number of appealing molecular properties from a drug discovery and development standpoint. As shown in Figure 5A, JS6 can readily synthesized in two high-yielding chemical steps at room temperature from commercially available and inexpensive starting materials. This is an important consideration when progressing new drug candidates into full preclinical development, where multi-gram quantities of pure material are needed for ongoing in vivo efficacy and toxicology studies. JS6 is fully compliant with the common "rules of thumb" used by pharmaceutical chemists to guide drug candidate selection, such as the Lipinski rule-of-five for prediction of oral activity (49). In addition, JS6 does not present solubility issues within the in vitro and in vivo delivery vehicles used to date. The utility of the morpholine group as a popular option for improving water solubility of drug candidates (either as free base or salt form) is well established in drug discovery laboratories (50). Finally, the chemical structure of JS6 provides no obvious toxicological flags (e.g, functional groups associated with metabolic instability or genotoxicity) or promiscuous artifact groups known as pan-assay interference compounds (PAINS) (51).

Overall, the molecular properties of JS6 provide a basis for efforts to expand this work towards a first-in-class clinical candidate for patient administration.

\section{Acknowledgements}

This work was supported by Cardiff University, through a President's Scholarship PhD Studentship to J.S., and through infrastructure support to the School of Pharmacy and Pharmaceutical Sciences (A.B. and A.D.W.) and European Cancer Stem Cell Research Institute / School of Biosciences (R.W.E.C.). We thank Tiziana Life Sciences for PhD studentship support to D.T. and W.Y.; and postdoctoral funding to A.G. Funding for a PhD studentship to C.B. was provided by Cancer Research Wales. Additional running costs were supported by donations from the Breast Cancer Research Aid (UK charity number 1166674) We acknowledge infrastructure support from the Wales Cancer Research Centre (to L.P.) and the Life Science Research Network Wales.

\section{Competing interests}

RC, AW and AB were scientific advisers of Tiziana Life Sciences plc from 2014 to 2017. The other authors declare that they have no competing interests. The work described here has led to the filing of patent application WO2015014972 A1, "2-Benzoylaminobenzamide derivatives as bcl-3 inhibitors" (inventors A.D.W., A.B., R.W.E.C, and J.S., publication date February 5, 2015).

\section{REFERENCES:}

1. Anderson RL, Balasas T, Callaghan J, Coombes RC, Evans J, Hall JA, et al. A framework for the development of effective anti-metastatic agents. Nat Rev Clin Oncol. 2019;16(3):185204.

2. Steeg PS. Targeting metastasis. Nat Rev Cancer. 2016;16(4):201-18. 
3. Li Q, Yan H, Zhao P, Yang Y, Cao B. Efficacy and Safety of Bevacizumab Combined with Chemotherapy for Managing Metastatic Breast Cancer: A Meta-Analysis of Randomized Controlled Trials. Sci Rep. 2015;5:15746.

4. Kaufman PA, Awada A, Twelves C, Yelle L, Perez EA, Velikova G, et al. Phase III openlabel randomized study of eribulin mesylate versus capecitabine in patients with locally advanced or metastatic breast cancer previously treated with an anthracycline and a taxane. $J$ Clin Oncol. 2015;33(6):594-601.

5. Verma S, Miles D, Gianni L, Krop IE, Welslau M, Baselga J, et al. Trastuzumab emtansine for HER2-positive advanced breast cancer. N Engl J Med. 2012;367(19):1783-91.

6. Eckhardt BL, Francis PA, Parker BS, Anderson RL. Strategies for the discovery and development of therapies for metastatic breast cancer. Nat Rev Drug Discov. 2012;11(6):47997.

7. Early Breast Cancer Trialists' Collaborative Group (EBCTCG). Adjuvant bisphosphonate treatment in early breast cancer: meta-analyses of individual patient data from randomized trials. Lancet 2015;386: 1353-1361.

8. Sadok A, McCarthy A, Caldwell J, Collins I, Garrett MD, Yeo M, et al. Rho kinase inhibitors block melanoma cell migration and inhibit metastasis. Cancer Res. 2015;75(11):2272-84.

9. Friedl P, Wolf K. Tumour-cell invasion and migration: diversity and escape mechanisms. Nat Rev Cancer. 2003;3(5):362-74.

10. Gandalovicova A, Rosel D, Fernandes M, Vesely P, Heneberg P, Cermak V, et al. Migrastatics - Anti-metastatic and Anti-invasion Drugs: Promises and Challenges. Trends Cancer. 2017;3(6):391-406.

11. Turnham DJ, Yang WW, Davies J, Varnava A, Ridley AJ, Conlan RS, et al. Bcl-3 promotes multi-modal tumour cell migration via NF-kappaB1 mediated regulation of Cdc42. Carcinogenesis. 2020; 41:1432-43.

12. Ohno H, Takimoto G, McKeithan TW. The candidate proto-oncogene bcl-3 is related to genes implicated in cell lineage determination and cell cycle control. Cell. 1990;60(6):991-7.

13. Chang TP, Vancurova I. Bcl3 regulates pro-survival and pro-inflammatory gene expression in cutaneous T-cell lymphoma. Biochim Biophys Acta. 2014;1843(11):2620-30.

14. Wakefield A, Soukupova J, Montagne A, Ranger J, French R, Muller WJ, et al. Bcl3 selectively promotes metastasis of ERBB2-driven mammary tumors. Cancer Res. 2013;73(2):745-55.

15. Chen X, Cao X, Sun X, Lei R, Chen P, Zhao Y, et al. Bcl-3 regulates TGFbeta signaling by stabilizing Smad3 during breast cancer pulmonary metastasis. Cell Death Dis. 2016; 7(12):e2508.

16. Legge DN, Chambers AC, Parker TP, Timms P, Collard TJ, Williams AC. The role of B-Cell Lymphoma-3 (BCL-3) in enabling the hallmarks of cancer: implications for the treatment of colorectal carcinogenesis. Carcinogenesis 2020;41(30;249-56.

17. Thornburg NJ, Pathmanathan R, Raab-Traub N. Activation of nuclear factor-kappaB p50 homodimer/Bcl-3 complexes in nasopharyngeal carcinoma. Cancer Res. 2003;63(23):8293301.

18. Zou Y, Uddin MM, Padmanabhan S, Zhu Y, Bu P, Vancura A, et al. The proto-oncogene Bcl3 induces immune checkpoint PD-L1 expression, mediating proliferation of ovarian cancer cells. J Biol Chem. 2018;293(40):15483-96.

19. Ahlqvist K, Saamarthy K, Syed Khaja AS, Bjartell A, Massoumi R. Expression of Id proteins is regulated by the Bcl-3 proto-oncogene in prostate cancer. Oncogene. 2013;32(12):1601-8. 
20. Wu L, Bernal GM, Cahill KE, Pytel P, Fitzpatrick CA, Mashek H, et al. BCL3 expression promotes resistance to alkylating chemotherapy in gliomas. Sci Transl Med. 2018;10(448).

21. Wu J, Li L, Jiang G, Zhan H, Wang N. B-cell CLL/lymphoma 3 promotes glioma cell proliferation and inhibits apoptosis through the oncogenic STAT3 pathway. Int J Oncol. 2016;49(6):2471-9.

22. Legge DN, Shephard AP, Collard TJ, Greenhough A, Chambers AC, Clarkson RW, et al. BCL3 promotes a cancer stem cell phenotype by enhancing beta-catenin signalling in colorectal tumour cells. Dis Model Mech. 2019;12(3): dmm037697.

23. Schwarz EM, Krimpenfort P, Berns A, Verma IM. Immunological defects in mice with a targeted disruption in Bcl-3. Genes Dev. 1997;11(2):187-97.

24. Zhong M, Lee GM, Sijbesma E, Ottmann C, Arkin MR. Modulating protein-protein interaction networks in protein homeostasis. Curr Opin Chem Biol. 2019;50:55-65.

25. Perez EA. Microtubule inhibitors: Differentiating tubulin-inhibiting agents based on mechanisms of action, clinical activity, and resistance. Mol Cancer Ther. 2009;8(8):2086-95.

26. Valentin R, Grabow S, Davids MS. The rise of apoptosis: targeting apoptosis in hematologic malignancies. Blood 2018; $132: 1248-64$.

27. Collins PE, Kiely PA, Carmody RJ. Inhibition of transcription by B cell Leukemia 3 (Bcl-3) protein requires interaction with nuclear factor kappaB (NF-kappaB) p50. J Biol Chem. 2014;289(10):7059-67.

28. Keutgens A, Shostak K, Close P, Zhang X, Hennuy B, Aussems M, et al. The repressing function of the oncoprotein BCL-3 requires CtBP, while its polyubiquitination and degradation involve the E3 ligase TBLR1. Mol Cell Biol. 2010;30(16):4006-21.

29. Molecular Operating Environment (MOE) Integrated Computer-Aided Molecular Design Platform (Chemical Computing Group); www.chemcomp.com/Products.htm

30. Hess B, Kutzner C, van der Spoel D, Lindahl E. GROMACS 4: Algorithms for Highly Efficient, Load-Balanced, and Scalable Molecular Simulation. J Chem Theory Comput. 2008;4(3):435-47.

31. Schrodinger: Glide. 5.5 Edition. New York, NY (2009).

32. Korb O, Stutzle T, Exner T. Ant Colony Optimization and Swarm Intelligence. 5th International Workshop. In ANTS LNCS 2006;4150:247-258.

33. BiosolveITGmbH: FlexX 3.0. Sannkt Augustin, Germany.

34. Schwartz O, Virelizier JL, Montagnier L, Hazan U. A microtransfection method using the luciferase-encoding reporter gene for the assay of human immunodeficiency virus LTR promoter activity. Gene. 1990;88(2):197-205.

35. Clarkson RW, Heeley JL, Chapman R, Aillet F, Hay RT, Wyllie A, et al. NF-kappaB inhibits apoptosis in murine mammary epithelia. J Biol Chem. 2000;275(17):12737-42.

36. Cartwright T, Perkins ND, C LW. NFKB1: a suppressor of inflammation, ageing and cancer. FEBS J. 2016;283(10):1812-22.

37. Michel F, Soler-Lopez M, Petosa C, Cramer P, Siebenlist U, Muller CW. Crystal structure of the ankyrin repeat domain of Bcl-3: a unique member of the IkappaB protein family. $E M B O$ J. 2001;20(22):6180-90.

38. Keutgens A, Zhang X, Shostak K, Robert I, Olivier S, Vanderplasschen A, et al. BCL-3 degradation involves its polyubiquitination through a FBW7-independent pathway and its binding to the proteasome subunit PSMB1. J Biol Chem. 2010;285(33):25831-40.

39. Wulczyn FG, Naumann M, Scheidereit C. Candidate proto-oncogene bcl-3 encodes a subunitspecific inhibitor of transcription factor NF-kappa B. Nature. 1992;358(6387):597-9. 
40. Bours V, Franzoso G, Azarenko V, Park S, Kanno T, Brown K, et al. The oncoprotein Bcl-3 directly transactivates through kappa B motifs via association with DNA-binding p50B homodimers. Cell. 1993;72(5):729-39.

41. Franzoso G, Bours V, Azarenko V, Park S, Tomita-Yamaguchi M, Kanno T, et al. The oncoprotein Bcl-3 can facilitate NF-kappa B-mediated transactivation by removing inhibiting p50 homodimers from select kappa B sites. EMBO J. 1993;12(10):3893-901.

42. Jacobs MD, Harrison SC. Structure of an IkappaBalpha/NF-kappaB complex. Cell. 1998;95(6):749-58.

43. Bundy DL, McKeithan TW. Diverse effects of BCL3 phosphorylation on its modulation of NF-kappaB p52 homodimer binding to DNA. J Biol Chem. 1997;272(52):33132-9.

44. Pang H, Bartlam M, Zeng Q, Miyatake H, Hisano T, Miki K, et al. Crystal structure of human pirin: an iron-binding nuclear protein and transcription cofactor. $J$ Biol Chem. 2004;279(2):1491-8.

45. Kuwata H, Watanabe Y, Miyoshi H, Yamamoto M, Kaisho T, Takeda K, Akira S. IL-10inducible Bcl-3 negatively regulates LPS-induced TNF- $\alpha$ production in macrophages. Blood 2003; $102: 4123-9$.

46. Kashatus D, Cogswell P, Baldwin AS. Expression of the Bcl-3 proto-oncogene suppresses p53 activation. Genes Dev. 2006;20:225-35.

47. Kuphal S, Palm HG, Poser I, Bosserhoff AK. Snail-regulated genes in malignant melanoma. Melanoma Res. 2005;15(4):305-13.

48. Piggott L, Omidvar N, Perez S, Eberl M and Clarkson R. Suppression of apoptosis inhibitor cFLIP selectively eliminates breast cancer stem cell activity in response to the anti-cancer agent, TRAIL. Breast Cancer Research 2011;13:R88.

49. Lipinski CA. Rule of five in 2015 and beyond: Target and ligand structural limitations, ligand chemistry structure and drug discovery project decisions. Adv Drug Deliv Rev. 2016;101:3441.

50. Arshad F, Khan MF, Akhtar W, Alam MM, Nainwal LM, Kaushik SK, et al. Revealing quinquennial anticancer journey of morpholine: A SAR based review. Eur J Med Chem. 2019; $167: 324-56$.

51. Baell J, Walters MA. Chemistry: Chemical con artists foil drug discovery. Nature. 2014;513(7519):481-3.

52. Aslakson CJ, Miller FR. Selective events in the metastatic process defined by analysis of the sequential dissemination of subpopulations of a mouse mammary tumor. Cancer

Res 1992;52:1399-405 
Figure legends:

Figure 1. Computer-aided identification of a novel Bcl3 inhibitor. (A) Model of Bcl3/p50 complex (Bcl3 in cyan and pink; p50 in orange and magenta), built within the Molecular Operating Environment (MOE) platform (28). (B) Contact interface between Bcl3 and p50 in correspondence with ankyrin repeat 6-7 of $\mathrm{Bcl} 3$ (Bcl3 in blue; p50 in red). (C) Pharmacophore query used to filter through the SPECS compound library. (D) Docking pose of example virtual hit compound JS6 in the Bcl3 pocket.

Figure 2. Compound 6 (JS6) inhibits Bcl3:p50 protein binding at a concentration that is non-toxic to non-tumorigenic cells. (A) Bcl3 sandwich ELISA of lysates taken from HEK293 cells overexpressing Bcl3-FLAG, using immobilized FLAG-tag antibody and a Bcl3-specific detection antibody to determine Bc13 levels in each sample. HEK293 cells over-expressing FLAG-tagged Bcl3 were incubated with each of the 10 candidate compounds at $10 \mu \mathrm{M}(\mathrm{Bcl} 3+\mathrm{JS})$ or vehicle control (Bcl3) for 24 hours before ELISA. Signals were compared to untreated HEK293 cells expressing either FLAG-tagged Bcl3 $(+\mathrm{Bcl} 3)$, FLAG-tagged $\mathrm{Bcl} 3$ binding mutant (ANKmut) or empty vector control (-Bcl3). $n=5$ independent lysates. None of the compounds caused a significant decrease in $\mathrm{Bcl} 3$ expression by ELISA. (B) p50 sandwich ELISA of HEK293 cell lysates from (A), using immobilized FLAG-tag antibody and a specific NF- $\kappa \mathrm{B} 1(\mathrm{p} 50)$ antibody to detect p50:Bcl3-FLAG complexes. Signals were normalized to untreated, Bcl3 non-expressing controls. $\mathrm{n}=5$ independent lysates. Only JS6 $(10 \mu \mathrm{M})$ statistically suppressed $\mathrm{p} 50$ binding equivalent to the $\mathrm{Bcl} 3$ binding mutant (ANKmut). * ${ }^{*}<0.05$ vs $\mathrm{Bcl} 3$. $\mathrm{Bcl} 3+\mathrm{c} 6$ vs $\mathrm{Bcl} 3 \mathrm{p}=4 \times 10^{-5}$; $\mathrm{Bcl} 3+\mathrm{c} 6$ vs ANKmut $\mathrm{p}=0.86$. (C) Immunoprecipitation (IP) of $\mathrm{Bcl} 3$ or $\mathrm{p} 50$ from cell lysates of MDAMB-231 cells pre-treated with JS6 for 30 minutes or 2 hours in cell culture prior to cell lysis. Cells overexpressed either Bcl3, empty vector (pcDNA) or the ANK binding mutant (ANK). Histograms show mean of three independent IP experiments; * ${ }^{*}<0.05 * * p<0.012$. (D) CellTiter-Glo® (Sigma) viability assay of HEK293 cells incubated with $10 \mu \mathrm{M}$ each compound for 24 hours. JS6 (c6) was non-toxic (t-test $\mathrm{Bcl} 3$ vs Bcl3+c6, p=0.99) (E) CellTiter-Blue ${ }^{\circledR}$ viability assay of MDA-MB-231 triple-negative breast cancer cells incubated with $10 \mu \mathrm{M}$ each compound for 24 hours. JS6 exhibited a modest $(14 \%+/-8 \%)$ but significant decrease in cell viability (t-test $\mathrm{Bcl} 3$ vs $\mathrm{Bcl} 3+\mathrm{c} 6, \mathrm{p}=0.0094)$.

Figure 3. JS6 suppresses NF- $\kappa$ B signaling of breast cancer cells. NF- $\kappa B$-responsive promoter luciferase-reporter assay performed in (A,B) HEK293 cells; (C,D) HEK293 cells over-expressing NFкB2/p52; and (E,F) MDA-MB-231 breast cancer cells. (A,C,E) cells over-expressing Bcl3 were treated with $10 \mu \mathrm{M}$ JS6 (+Bcl3+JS6) or vehicle control (+Bcl3) for 24 hours prior to assessment of luciferase activity relative to LacZ transfection control. The effect of JS6 was compared to cells overexpressing the $\mathrm{Bcl} 3$ binding mutant (ANKmut) and non-expressing controls (-Bcl3). Bcl3+JS6 vs + Bcl3 $* \mathrm{p}=0.013 ; * * \mathrm{p}=0.021 ; * * * \mathrm{p}=0.0059$ : Bcl3+JS6 vs $-\mathrm{Bcl} 3$ n.s.. $\mathrm{n}=3$ independent lysates. (B,D,F) Dose response curves for JS6 in NF- $\kappa \mathrm{B}$ luciferase reporter assay for each of the cell lines. Signals were normalized to untreated $\mathrm{Bcl} 3$ over-expressing cells ( $\mathrm{Bcl} 3$ ) with cells over-expressing the binding mutant (ANKmut) used as negative controls. $\mathrm{IC}_{50}{ }^{\mathrm{HEK}}=159 \mathrm{nM}\left(1.4 \mu \mathrm{M}-0.18 \mathrm{nM}, 95 \%\right.$ conf. int.); $\mathrm{IC}_{50}{ }^{\mathrm{HEKp} 52}=$ $710 \mathrm{nM}\left(2.1 \mu \mathrm{M}-238 \mathrm{nM}, 95 \%\right.$ conf. int.); $\mathrm{IC}_{50}{ }^{231}=45 \mathrm{nM}$ (15 nM-136 nM, 95\% conf. int.). All error bars are S.E.M. from three independent experiments. (G) The relative gene expression of a selected panel of known Bcl3 responsive genes was quantified using TaqMan qRT-PCR probes in MDA-MB-231-Luc cells following either 48 hour knockdown with Bcl3 siRNA (vs scRNA) or 8 hour treatment with 10uM JS6 (vs DMSO control). All error bars are S.E.M. 
Figure 4. JS6 suppresses multi-modal migration of breast cancer cells (A,B) Transwell (Boyden chamber) assay of serum-induced MDA-MB-231 cell migration for 24 hours following over-expression of $\mathrm{Bcl} 3$ in the absence $(+\mathrm{Bcl} 3)$ or presence $(+\mathrm{Bcl} 3+\mathrm{JS} 6)$ of JS6 compared to non-overexpressing cells (-Bcl3), cells over-expressing the Bcl3 binding mutant (ANKmut) or cells in which Bcl3 over-expression was knocked down by siRNA ( $\mathrm{siBcl} 3$ ). Data represents relative number of cells counted in three fields of view (minimum 500 cells) in four independent experiments. Bcl3+JS6 vs + Bcl3 *p=0.036; Bcl3+JS6 vs -Bcl3 n.s. $\mathrm{IC}_{50}=310 \mathrm{nM}(119 \mathrm{nM}-806 \mathrm{nM}, 95 \%$ conf. int.). (C) Single-cell (mesenchymal) migration of MDAMB-436 cells determined by time-lapse microscopy of pre-confluent cells following 10uM JS6 treatment versus control (DMSO). Minimum 30 cells tracked. (D-F) Collective sheet (wound-healing) assay of confluent monolayers of MDA-MD-231, MDA-MB-436 and BT474 breast cancer cells treated with 10uM or $50 \mathrm{uM} \mathrm{JS6}$ or JS1. $\mathrm{N}=$ minimum of 7 independent experiments. ${ }^{*}=\mathrm{p}<0.10,{ }^{* *}=\mathrm{p}<0.05$. Error bars are SEM.

Figure 5. JS6 suppresses primary growth and secondary tumor colonisation in xenograft models of metastatic breast cancer. (A) Synthetic route to JS6. Reagent and conditions: (a) pyridine, $25^{\circ} \mathrm{C}, 5$ hours; (b) 2-morpholinoethan-1-amine, $i \mathrm{Pr}_{2} \mathrm{NH}$ (DIPEA), DMF, $25^{\circ} \mathrm{C}, 18$ hours. (B) Experimental design of an in vivo model of metastatic breast cancer. JS6 $(3.5 \mathrm{mg} / \mathrm{Kg})$ or vehicle control (1\% DMSO) were given as a single i.p. injection daily for 10 days beginning 24 hours after xenograft, and scanned for luciferase activity on the days shown (S). (C) The relative tumor burden (measured by total thoracic luciferase flux) of JS6 treated animals at 28 days post-xenograft is represented as the percentage of the mean of controls in $n=3$ independent experiments, consisting of between 3 and 5 animals per treatment arm in each experiment. (D) Representative image of luciferase scans from one of the 3 experimental cohorts at day 28. The missing mouse from this control group was found dead prior to scanning and subsequent examination showed a heavy tumor burden in lungs and liver (data not shown). Tumor burden in this control mouse is not included in the final data set. (E) Kinetics of secondary tumor burden in one of 3 independent experiments, normalized to the mean luciferase activity at day 28 of controls in all 3 experiments. (F) Waterfall plot illustrating normalized thoracic luciferase activity in all animals across the 3 experiments ( $n=12$ controls, $n=13$ JS6 treated mice). (G) Experimental design of in vivo models of orthotopic tumor colonization and expansion. MDA-MB-436 cells were injected into the abdominal fat pads of recipient mice and after 24 hours JS6 was injected i.p. daily for the course of the experiment. Caliper measurement of tumors were performed on the days shown $(\mathrm{t})$. (H) Mean tumor growth kinetics for controls $(n=11)$ and JS6 treated $(n=12)$ tumors. A statistically significant difference in tumor size was observed from day 58 to the end of the experiment (t-test, $* \mathrm{p}<0.05)$. (I) Waterfall plot illustrating individual tumor volumes at day 76. (J) Immunohistochemistry performed on control and JS6 treated tumors harvested on day 76. Representative images of cleaved caspase 3 (CC3) and phosphorohistone $\mathrm{H} 3(\mathrm{pH} 3)$ immunoreactivity and quantification of the proportion of positive cells from at least 3000 cells counted. *Statistically significant differences were observed in CC3 sections only. The relative change in cell turnover index following JS6 treatment (deltaCTI $=[\mathrm{pH} 3 / \mathrm{CC} 3]^{\mathrm{SS} 6} /[\mathrm{pH} 3 / \mathrm{CC} 3]^{\mathrm{DMSO}}$ ) is shown. All error bars are S.E.M. 
Figure 6. JS6 suppresses tumor growth and secondary tumor burden in an immune-competent model of spontaneous metastasis. Metastatic 4T1.2 murine carcinoma cells (52) were orthotopically transplanted in to immune competent Balb/c mice and mice injected (i.p.) daily with JS6 (10mg/Kg and $3.5 \mathrm{mg} / \mathrm{Kg}$ ) or vehicle (DMSO) for 27 days. (A) Tumor volume determined by caliper measurement (B) average tumor sizes at end of study (28 days) (C) total number of metastatic lesions identified per section of lung tissue ( $n=7)$ and (D) size of identified lesions in the same sections determined by number of cells (nuclei) per tumor focus. (E) Colony formation assay of MDA-MB-436 cells grown in low density adherent culture for 10 days in the presence of a range of doses of JS6 or DMSO control. Representative images of 6 independent replicates are shown. Graphs show mean data on colony number (more than 32 cells per colony) and overall colony size. Error bars in all figures are SEM. ${ }^{*}=\mathrm{p}<0.05,{ }^{*}=\mathrm{p}<0.01$, $* * *=p<0.005$. 

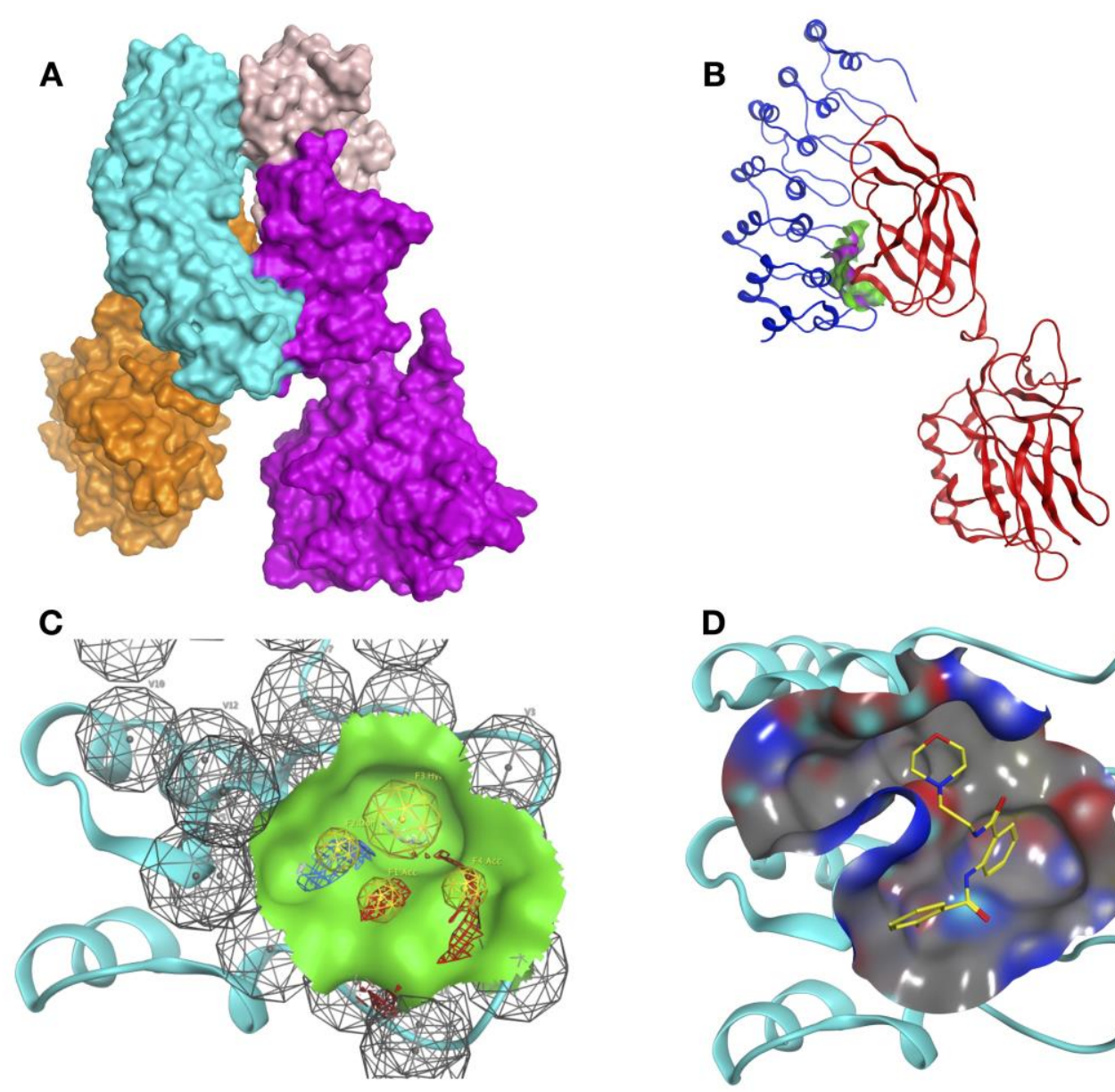

Figure 1.

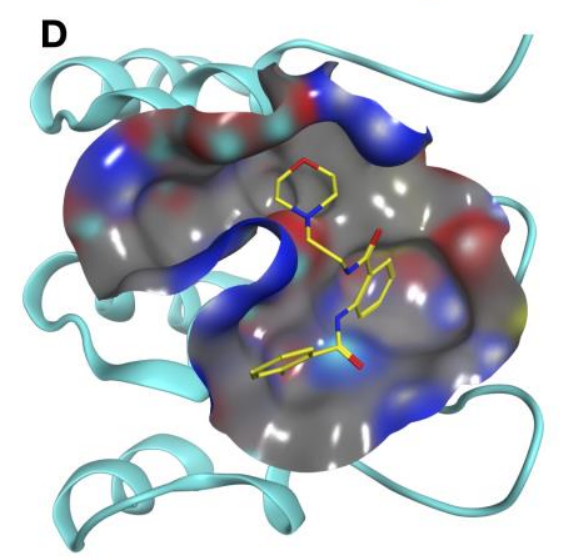


A

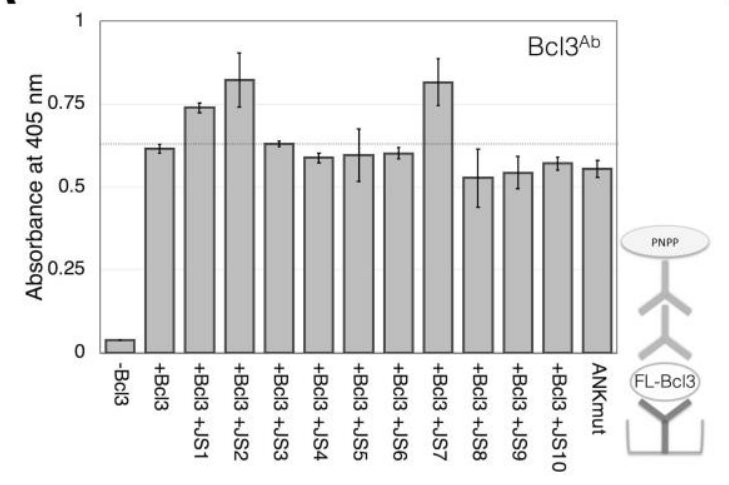

B

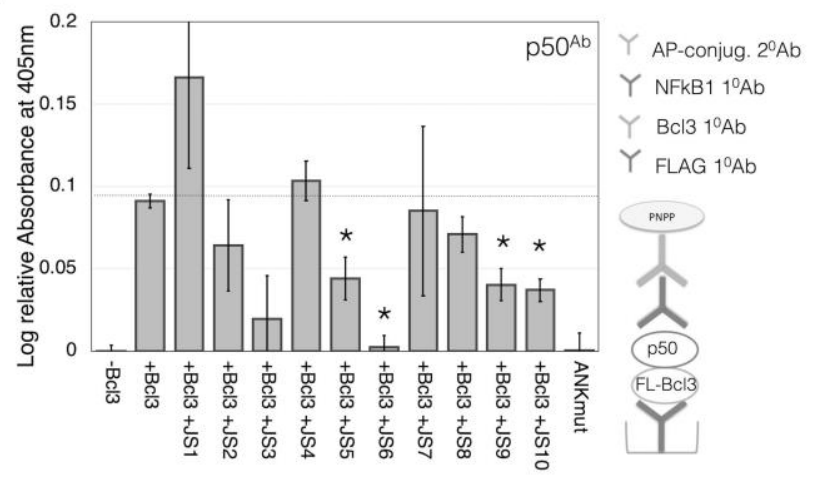

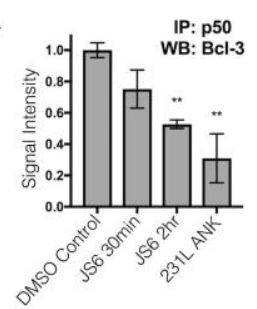

D

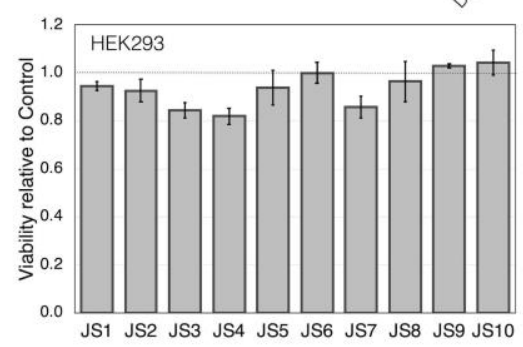

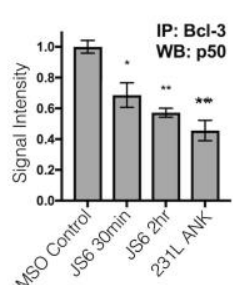

E

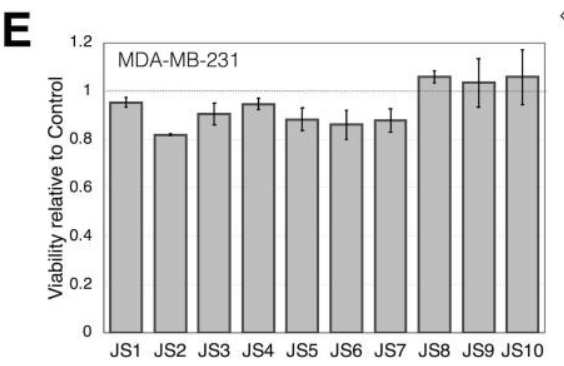

Figure 2. 
A

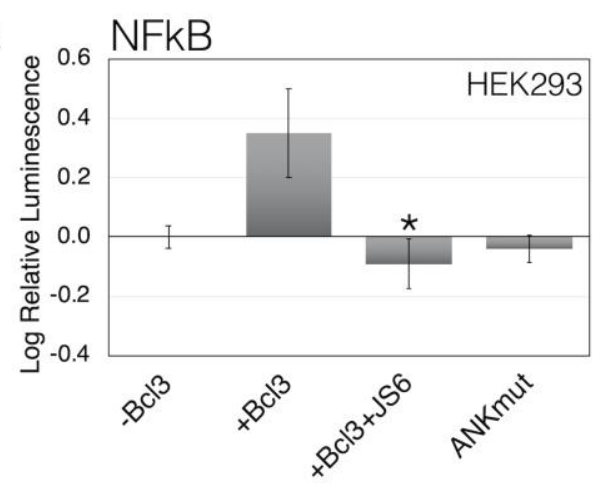

c

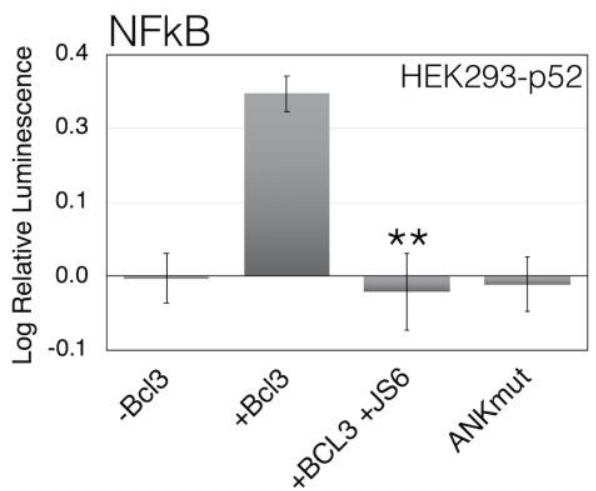

E

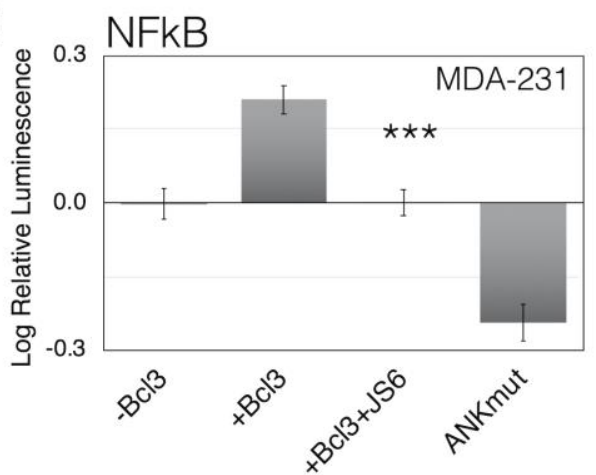

B

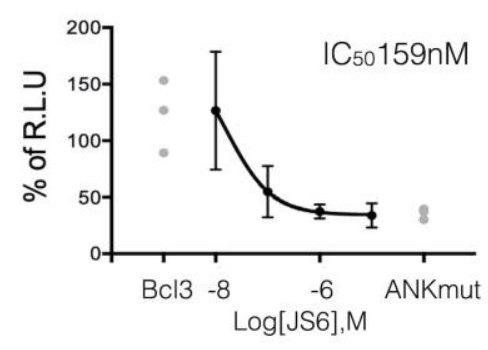

D

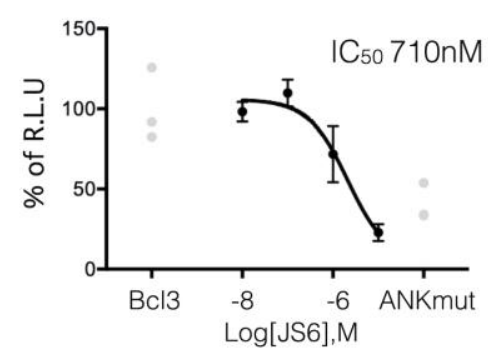

$F$

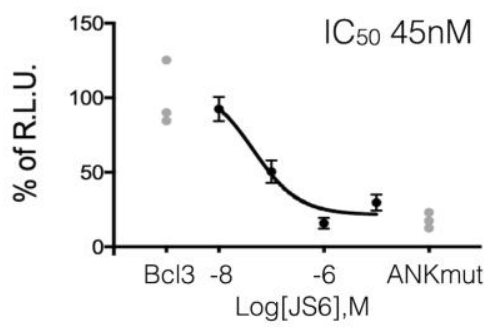

\section{G}

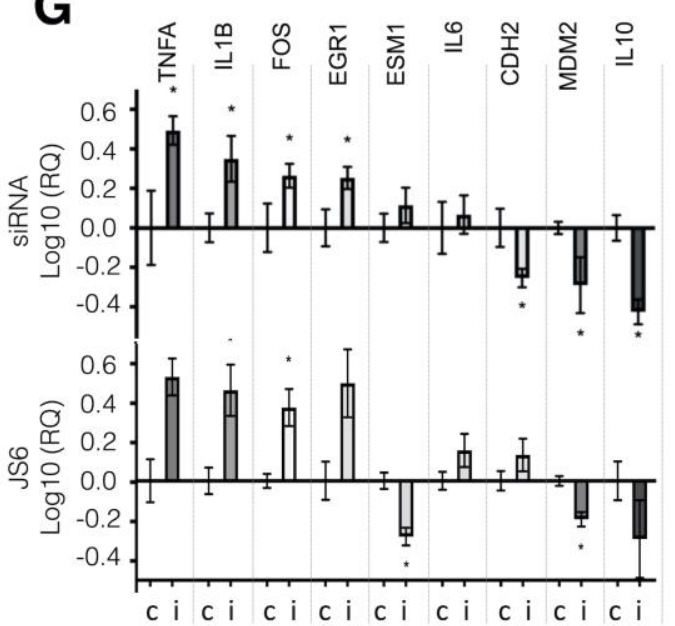

Figure 3. 
A

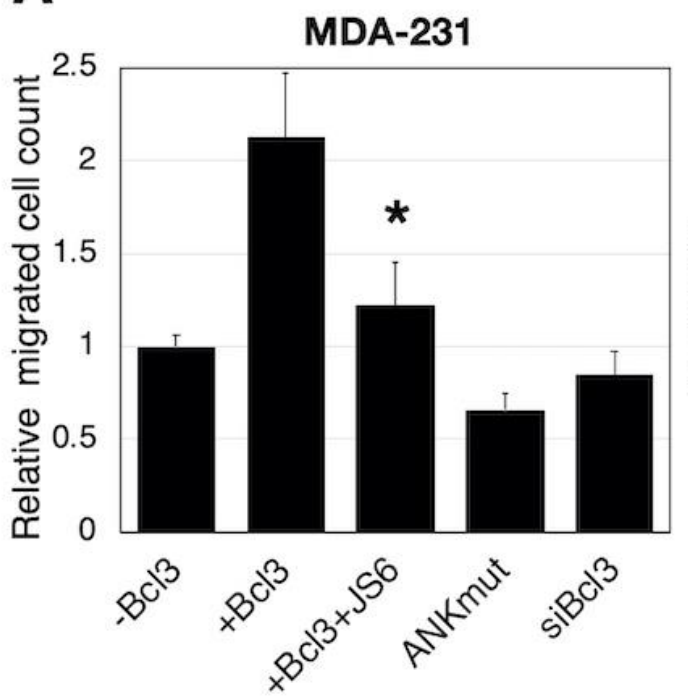

B
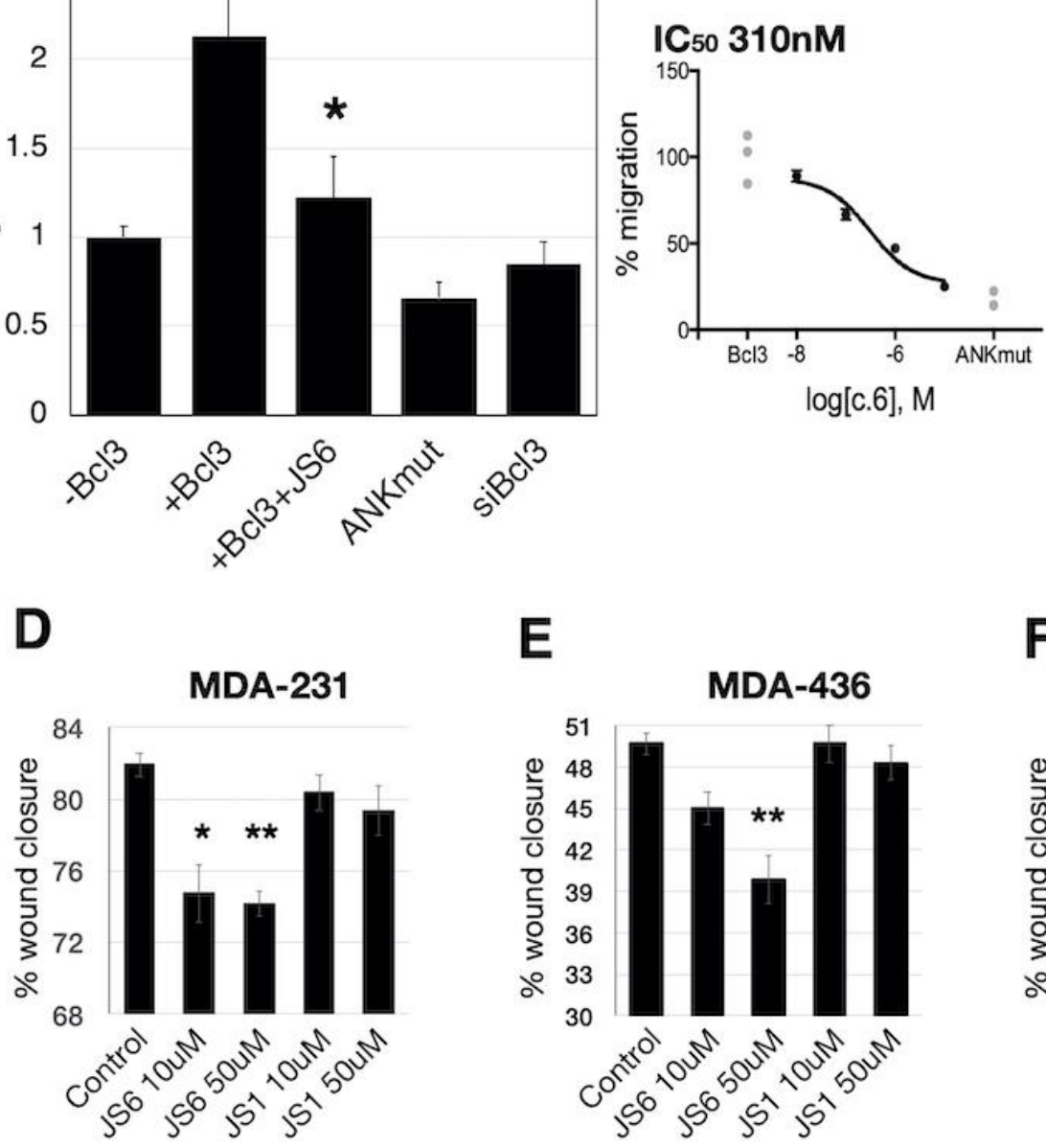

E

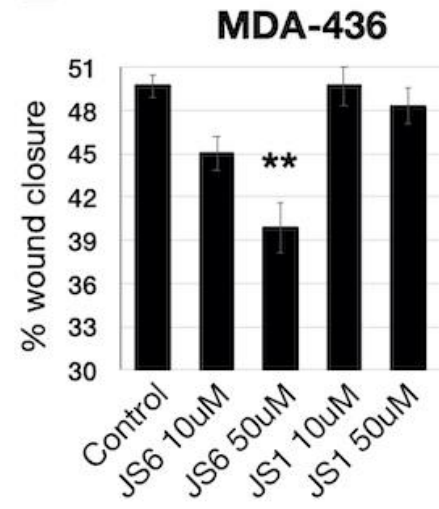

C

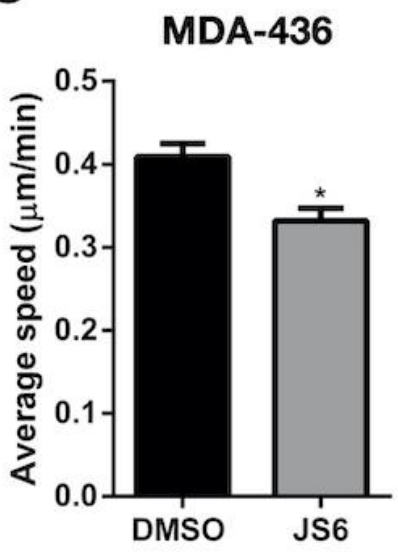

F

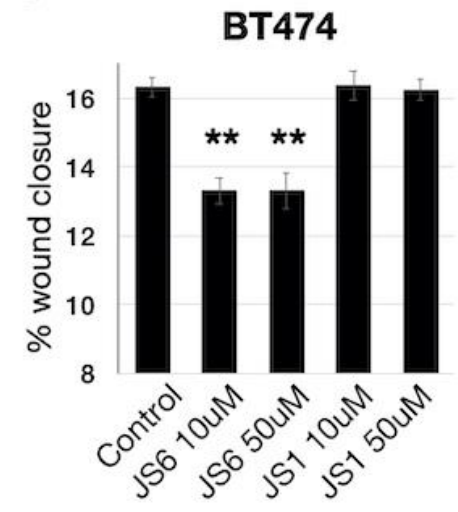

Figure 4. 
A
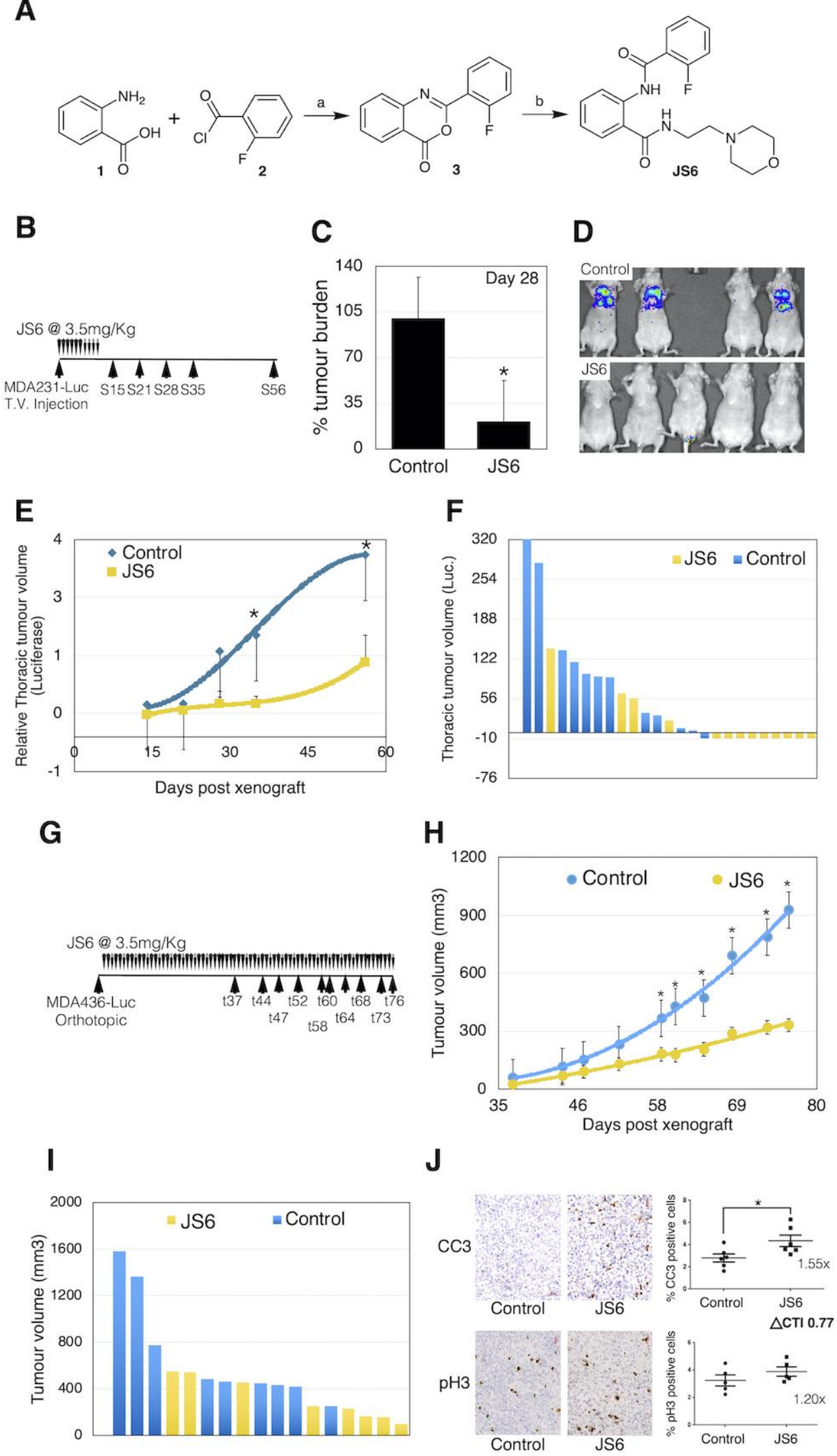

Figure 5. 
A
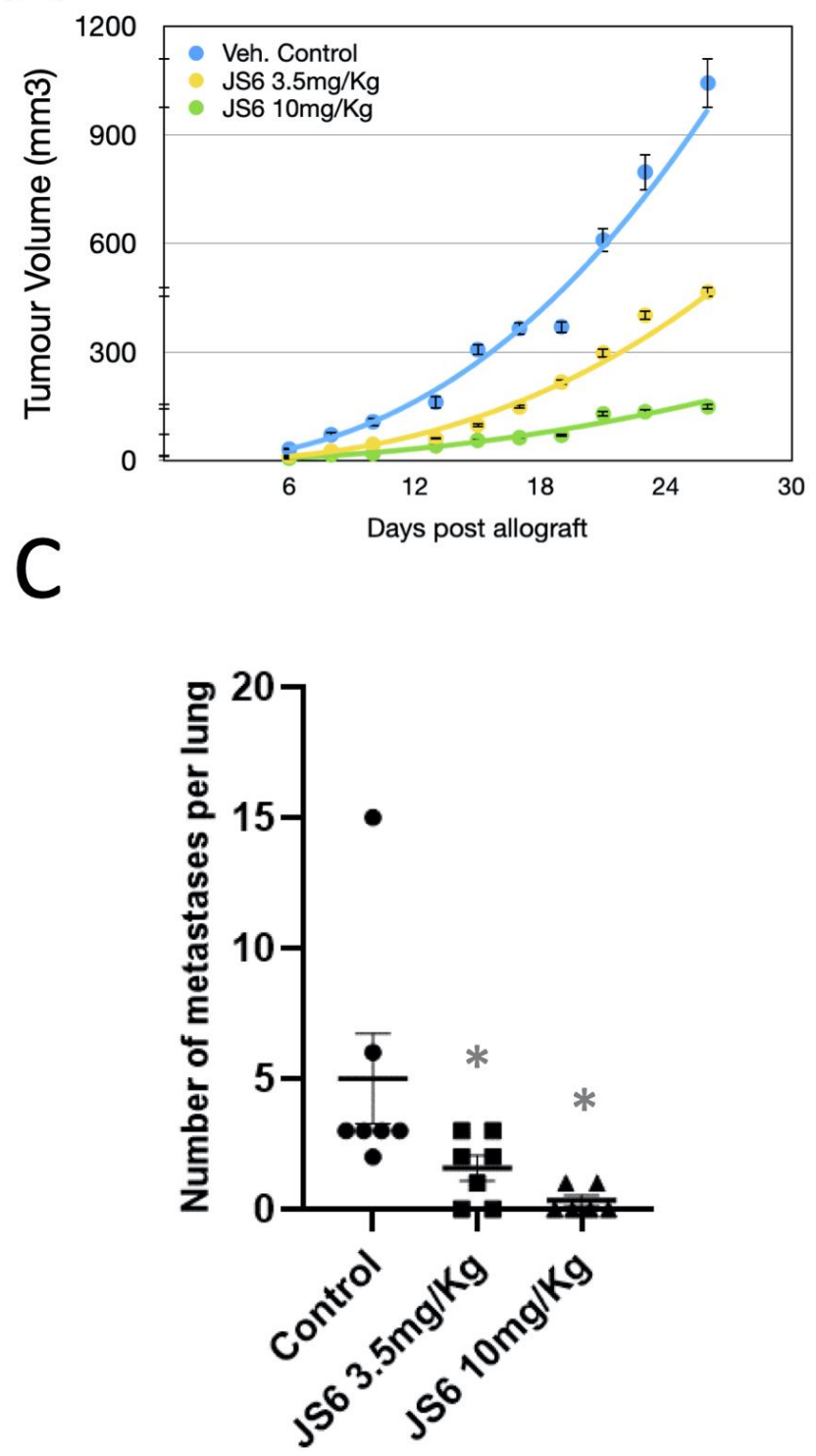

E

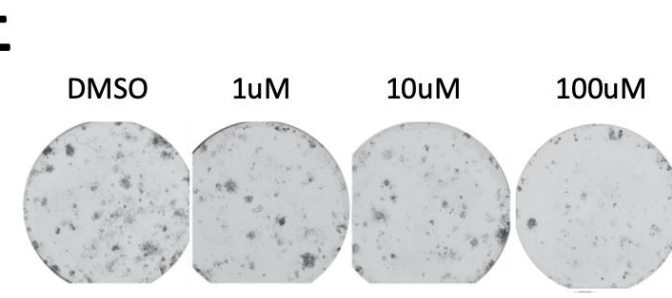

Figure 6.
B
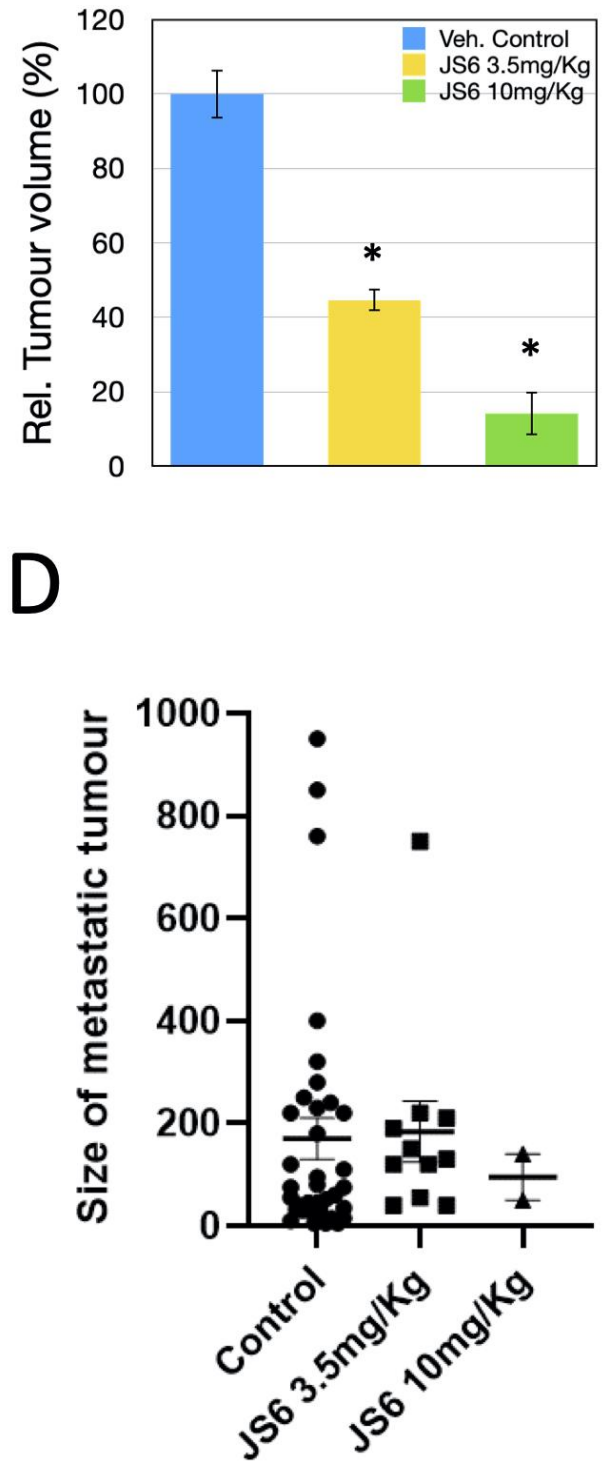